\title{
La Universidad de Mérida y el fortalecimiento del clero secular en Yucatán, siglos XVII-XVIII
}

\section{The University of Merida and the Strengthening of the Secular Clergy in Yucatan, 17th-18th Centuries}

\author{
Rafael PATRÓN SARTI \\ https://orcid.org/0000-0002-6989-3447 \\ Universidad Autónoma de Yucatán (México) \\ rafaelpatronsa@gmail.com
}

Rodolfo AGUIRRE SALVADOR

https://orcid.org/0000-0003-1698-1264

Universidad Nacional Autónoma de México (México)

Instituto de Investigaciones sobre la Universidad y la Educación

aguirre_rodolfo@hotmail.com

\section{Resumen}

En el siglo XVII hubo una oleada de aperturas de universidades en la América hispana a cargo de jesuitas y dominicos. En la historiografía aún falta mucho por saber del papel que estas universidades, en manos de religiosos, desempeñaron en las sociedades. El presente artículo pone como ejemplo a la Universidad de Mérida de Yucatán, a cargo de la Compañía de Jesús, la cual abrió sus puertas en 1624. Por una parte, analiza la importancia de las cátedras y los grados de la universidad jesuita en la formación y el ascenso eclesiástico del clero secular del obispado. Y por la otra, explica el gran interés que tuvo el obispado de Yucatán en la buena marcha de esa universidad, al ser el principal semillero de la clerecía y parte de un proyecto más amplio para secularizar las doctrinas franciscanas en beneficio de la Iglesia diocesana. Palabras clave: clero secular; grados universitarios; Iglesia; Yucatán; Universidad de Mérida.

\begin{abstract}
In the 17th century there was a wave of university openings in Hispanic America by Jesuits and Dominicans. In historiography, much remains to be known about the role that these universities, in the hands of religious, played in societies. This article gives the example of the University of Merida of Yucatan, in charge of the Society of Jesus, which opened its doors in 1624. On the one hand, it analyzes the importance of the professorships and degrees of the Jesuit university in the formation and ecclesiastical rise of the secular clergy of the bishopric. And on the other, it explains the great interest that the bishopric of Yucatan had in the smooth running of that university, as it was the main hotbed of the clergy and part of a larger project to secularize Franciscan doctrines for the benefit of the diocesan Church.
\end{abstract}

Keywords: secular clergy; university degrees; Church; Yucatan; University of Merida.

Recepción: 15 de abril de 2020 | Aceptación: 3 de septiembre de 2020 
Una de las grandes preocupaciones de la Iglesia católica en la era moderna fue lograr una formación satisfactoria de sacerdotes en lo académico y doctrinal, además de hallar individuos con vocación eclesiástica al servicio de la feligresía. De ahí que en el concilio ecuménico de Trento, finalizado en 1563, se dedicaron importantes decretos al respecto. ${ }^{1}$ El asunto tuvo la misma importancia en América con la instauración de obispados, catedrales, provincias religiosas, conventos, doctrinas y parroquias, que requerían de un ejército de clérigos y religiosos. Si al principio los evangelizadores y curas fueron originarios de la península española, con el aumento de las instituciones eclesiásticas a través del tiempo, era inviable que los nuevos operarios siguieran proviniendo de ultramar en mayor medida. De ahí que pronto, diferentes corporaciones eclesiásticas comenzaron a discutir y planear la formación local de sacerdotes. En 1536, por ejemplo, se fundó el colegio para indios nobles de Santa Cruz de Tlatelolco en la ciudad de México, uno de cuyos objetivos fue la posible formación de religiosos nativos. ${ }^{2}$ Si bien esta meta no se logró, sí marcó el inicio de futuros proyectos formativos, tanto en obispados como en provincias religiosas.

En la península de Yucatán no hubo excepción. Desde el siglo Xvi, la incipiente sociedad hispánica buscó que sus descendientes tuvieran estudios conforme a los modelos europeos. Fundada Mérida en 1542, se dio paso a la creación de instituciones civiles y eclesiásticas que necesitaban letrados en sus filas. Sin embargo, más allá de los estudios que los franciscanos crearon para sus propios miembros, en el resto de esa centuria se careció de alguna sede para la formación de clérigos y sólo hubo esporádicos cursos de gramática y otras materias que algunos maestros dictaron. Quienes desearon estudios mayores y grados tuvieron que acudir a colegios y universidades del centro de Nueva España o de Castilla.

No obstante, en el siglo Xviı las expectativas educativas en Yucatán se favorecieron con la apertura, en 1618, de un colegio de la Compañía de Jesús en Mérida, por un lado, y porque los jesuitas gestionaron que sus

${ }^{1}$ Rodolfo Aguirre Salvador, "Formación y ordenación de clérigos ante la normativa conciliar. El caso del arzobispado de México, 1712-1748”, en Los concilios provinciales en Nueva España. Reflexiones e influencias, coordinación de María del Pilar Martínez López-Cano y Francisco Javier Cervantes Bello (México: Universidad Nacional Autónoma de México, Instituto de Investigaciones Históricas; Puebla: Benemérita Universidad Autónoma de Puebla, 2005), 337-362.

${ }^{2}$ Robert Ricard, La conquista espiritual de México: ensayo sobre el apostolado y los métodos misioneros de las órdenes mendicantes en la Nueva España de 1523-1524 a 1572 (México: Fondo de Cultura Económica, 2005), 342-349. 
colegios en Indias pudieran conferir grados académicos, por el otro. El monarca accedió así como el papa. El breve papal de concesión de grados fue emitido en 1621 y la cédula real que lo confirmó se promulgó en 1622. Finalmente, en 1624 se fundó la universidad en el colegio jesuita de Mérida, la cual funcionó hasta la expulsión de la Compañía en 1767.

La creación de la universidad de Mérida en 1624 fue muy relevante cuando se advierte que en el resto de Nueva España, exceptuando a la de México, no hubo otro establecimiento que haya otorgado grados sino hasta 1792, cuando se fundó la de Guadalajara. Si bien la de Yucatán fue universidad con solamente las facultades de Filosofía y Teología, ${ }^{3}$ con ellas bastaba para la formación académica de un clero secular local. El contar con una institución otorgante de grados de Filosofía y Teología fue muy importante para la población hispánica, pues facilitaba la promoción académica, eclesiástica y social de la juventud peninsular. Carente de minas y tierras fértiles, Yucatán tuvo pocas opciones económicas para los descendientes españoles, por lo que la carrera eclesiástica, especialmente la parroquial, fue una opción deseable dado que se esperaba la fundación de múltiples curatos de indios. ${ }^{4}$ El ser cura beneficiado significaba el acceso a las obvenciones y derechos parroquiales de los omnipresentes pueblos de indios.

El objetivo central de este trabajo es analizar la importancia de las cátedras y los grados de la universidad jesuita en la formación y ascenso eclesiástico del clero secular del obispado de Yucatán. Para el caso de la Real Universidad de México, se han realizado varios estudios sobre las carreras de sus graduados en las últimas dos décadas. ${ }^{5}$ Aguirre concluyó

\footnotetext{
${ }^{3}$ Enrique González González, El poder de las letras. Por una historia social de las universidades de la América hispana en el periodo colonial, en colaboración con Víctor Gutiérrez Rodríguez (México: Universidad Nacional Autónoma de México, Instituto de Investigaciones sobre la Universidad y la Educación; Puebla: Benemérita Universidad Autónoma de Puebla; México: Universidad Autónoma Metropolitana; México: Ediciones Educación y Cultura, 2017), 54.

${ }^{4}$ Adriana Rocher Salas, "Clero y élites en Yucatán durante el periodo colonial”, en Grupos privilegiados en la península de Yucatán, siglos XVIII y XIX, coordinación de Laura Machuca Gallegos (México: Centro de Investigaciones y Estudios Superiores en Antropología Social; Mérida: Secretaría de Cultura y las Artes de Yucatán, 2014), 44-49; Adriana Rocher Salas, "Las doctrinas de indios: la llave maestra del Yucatán colonial”, en La Iglesia hispanoamericana en la época colonial, coordinación de Rodolfo Aguirre Salvador y Lucrecia Enríquez (México: Universidad Nacional Autónoma de México, Instituto de Investigaciones sobre la Universidad y la Educación; Santiago de Chile: Pontificia Universidad Católica de Chile; México: Plaza y Valdés, 2008), 71-98.

${ }^{5}$ González González, El poder de las letras, 109-151.
} 
que la mayoría de aquellos que hicieron carrera fueron clérigos seculares. ${ }^{6}$ Para el caso de Yucatán, un primer estudio que tocó el tema de los clérigos graduados determinó que, para el periodo 1750-1800, los sacerdotes graduados en Artes y Teología fueron $42 \%$ y $9 \%$ respectivamente. Sin embargo, no detalló si los grados fueron de bachiller, licenciado o doctor ni acusó el cierre de la universidad jesuita en 1767, lo que seguramente se reflejó en las exiguas cifras. $^{7}$ William B. Taylor, citando el trabajo de Raymond P. Harrington, destacó que mientras que los concursantes a curatos en México y Guadalajara casi todos contaban con el grado de bachiller en el periodo colonial tardío (1780-1814), en el caso de Yucatán el porcentaje sólo llegó a 37\%. ${ }^{8}$ Sin embargo, tampoco reparó en que durante esos años la universidad en Mérida ya había cerrado sus puertas. En años recientes, afortunadamente, se han publicado importantes estudios sobre el clero secular de Yucatán, como el de Medina Suárez ${ }^{9}$ o los de Rocher Salas, para ambos cleros. ${ }^{10}$

De esa manera, en Yucatán, como sucedió en otros obispados novohispanos, la demanda de grados universitarios tuvo una estrecha relación con la búsqueda de algún beneficio eclesiástico, especialmente las parroquias. De ahí que los clérigos hayan constituido el sector estudiantil más importante de la universidad jesuita y con el que mejor se identificó. Así, nos

${ }^{6}$ Rodolfo Aguirre Salvador, "El ascenso de los clérigos de Nueva España durante el gobierno del arzobispo José Lanciego y Eguilaz”, Estudios de Historia Novohispana, 22 (2000): 77; Rodolfo Aguirre Salvador, El mérito y la estrategia. Clérigos, juristas y médicos en la Nueva España (México: Universidad Nacional Autónoma de México, Centro de Estudios sobre la Universidad; México: Plaza y Valdés Editores, 2003), 279.

7 Michael Joseph Fallon, "The Secular Clergy in the Diocese of Yucatan: 1750-1800" (tesis de doctorado, The Catholic University of America, Washington, 1979), 86-87.

${ }^{8}$ Raymond P. Harrington, "The Secular Clergy in the Diocese of Mérida de Yucatán, 1780-1850: Their Origins, Careers, Wealth and Activities" (tesis de doctorado, The Catholic University of America, Washington, 1982), 79 y 135. Harrington menciona que los grados que otorgó el Seminario de San Ildefonso en el periodo estudiado fueron bachiller en Artes y "pasantes" en Teología. No hay constancia de que el seminario diocesano haya otorgado grados universitarios en la época colonial. También concluyó que, entre 1780-1814, el 34\% de los curas con preparación formal se graduó en artes y sólo el 3\% en teología. Citado en William B. Taylor, Ministros de lo sagrado. Sacerdotes y feligreses en el México del siglo XVIII (México: El Colegio de Michoacán; México: Secretaría de Gobernación; México: El Colegio de México, 1999), v. I, 142, nota 89.

${ }^{9}$ Víctor Hugo Medina Suárez, "La consolidación del clero secular en el obispado de Yucatán, siglo XVıIı" (tesis de doctorado en Historia, El Colegio de Michoacán, Zamora, 2014).

10 Adriana Rocher Salas, "Frailes y clérigos en Yucatán. Siglo Xviı", Hispania Sacra, 55 (2003): 599-625. 
interesa explicar el gran interés que para el obispado de Yucatán tuvo la buena marcha de la universidad jesuita, al ser el semillero de sus cuadros clericales, y parte de un proyecto más amplio de secularizar las doctrinas franciscanas y sustituirlas por parroquias seculares, meta complicada debido al enorme poder e influencias de los franciscanos.

\section{La Iglesia, el sacerdocio y los grados académicos}

Las relaciones entre las universidades y las instituciones eclesiásticas provienen de la Europa medieval, cuando los papas fomentaron la creación y la consolidación de las primeras, brindándoles privilegios y dando cargos y prebendas a sus graduados. En la península ibérica no fue diferente: los graduados de las universidades de Salamanca o Valladolid, por ejemplo, fueron favorecidos con altos cargos eclesiásticos. Inversamente, al interior de las universidades hubo desde entonces también una presencia clerical en las cátedras y otros cargos universitarios. ${ }^{11}$ Hubo, pues, intereses comunes entre la Iglesia y las universidades por formar cuadros de clérigos para la renovación de las instituciones eclesiásticas.

Ya en el Nuevo Mundo, el siglo xvi presenció el nacimiento de universidades bajo el patronazgo del rey, como las de Lima o México en 1551. El interés de la monarquía española en fundarlas no fue gratuito, pues se comenzaron a requerir más letrados universitarios para la instauración de las instituciones reales en el ámbito indiano. Así, las universidades de la época moderna, como lo señaló Kagan, se convirtieron en semilleros de funcionarios y clérigos al servicio de los reyes y la Iglesia. ${ }^{12}$

Respecto de la formación de clérigos para la Iglesia novohispana, desde la década de 1530 hubo una preocupación de las órdenes religiosas por preparar frailes. Por esos años, la atención se centró en si los indios debían o no ordenarse. Los franciscanos fueron más lejos al fundar el Colegio de Tlatelolco y demostrar la capacidad de los naturales para tales destinos. No obstante, fue un intento fallido por razones políticas y culturales. ${ }^{13} \mathrm{En}$ cambio, pronto se abrieron noviciados de las órdenes religiosas para la formación de frailes españoles. Por lo que respecta a la formación del clero

${ }^{11}$ Mariano Peset y Juan Gutiérrez Cuadrado, "Clérigos y juristas en la Baja Edad Media castellano-leonesa”, Senara. Revista de Filología, anexo 2, v. 3 (1981), 7-66.

12 Richard L. Kagan, Universidad y sociedad en la España moderna (Madrid: Tecnos, 1981).

${ }^{13}$ Ricard, La conquista espiritual de México, 342-349. 
secular, los primeros obispos carecieron de los recursos, instituciones y hombres suficientes para ello. Al faltarle escuelas o seminarios propios para la formación sacerdotal, la Iglesia diocesana vio en las cátedras universitarias una salida. Aunque en el Concilio de Trento de 1563 se decretó la fundación de colegios seminarios en las diócesis, su ejecución quedó relegada por distintas razones económicas y políticas. ${ }^{14}$

En Madrid, Felipe II decretó una cédula en 1574, conocida en adelante como del Real Patronato, en donde privilegió a los letrados en los nombramientos para dignidades, canonjías y prebendas de las catedrales, si bien no se mencionó el mismo requisito para las parroquias. ${ }^{15}$ En la normativa conciliar, Trento y el tercer concilio mexicano, tampoco hay mención de los grados como requisito para la ordenación sacerdotal. ${ }^{16}$ Con todo, la tendencia posterior fue que los párrocos debían también contar con al menos un grado de bachiller. En el ámbito eclesiástico, la formación académica en latín, filosofía y teología era muy apreciada por la jerarquía; de ahí que la prueba exigida a los clérigos para demostrar esos conocimientos fuera un grado universitario.

En general, un grado universitario daba a quien lo poseía, formalmente, los conocimientos necesarios para ejercer una profesión. Un clérigo letrado normalmente tenía mejores oportunidades de empleo que aquel que no tuviera grado. Ello lo sabía muy bien el alto clero novohispano, en donde casi todos los jerarcas eran doctores. Los prelados solían favorecer más a presbíteros con buenas trayectorias académicas en las ciudades que a los curas rurales. Pero aun a aquellos clérigos sin deseos de hacer carrera eclesiástica un grado les podía abrir otras puertas fuera de las instituciones eclesiásticas. No sería raro hallar a muchos bachilleres clérigos alejados de tareas espirituales para quienes el grado quizá fue más importante. ${ }^{17}$

${ }^{14}$ Rodolfo Aguirre Salvador, Un clero en transición. Población clerical, cambio parroquial y política eclesiástica en el arzobispado de México, 1700-1749 (México: Universidad Nacional Autónoma de México, Instituto de Investigaciones sobre la Universidad y la Educación; México: Bonilla Artigas Editores; Madrid: Iberoamericana Vervuert, 2012), 28-31.

15 “...Queremos que para las dignidades, canonjías y prebendas de las iglesias catedrales de las Indias, en las presentaciones que hubiéremos de hacer, sean preferidos los letrados a los que no lo fueren...” Véase en Leticia Pérez Puente, Enrique González González y Rodolfo Aguirre Salvador, "Estudios, textos y anexos. I y II concilios", en Concilios provinciales mexicanos. Época colonial, coordinación de Pilar Martínez López-Cano, edición en disco compacto (México: Universidad Nacional Autónoma de México, Instituto de Investigaciones Históricas, 2004).

16 Aguirre Salvador, “Formación y ordenación de clérigos”, 337-362.

${ }^{17}$ Aguirre Salvador, Un clero en transición, 240-244. 
La universidad jesuita de Mérida: un espacio para la formación local de clérigos

Al llegar en 1562 a Yucatán su primer obispo, fray Francisco del Toral, encontró pocos clérigos seculares para nutrir su Iglesia. En la catedral de Mérida había dos capitulares: el deán y el chantre quienes, para completar sus ingresos, también eran curas ahí mismo. Las otras dos poblaciones importantes de españoles, Campeche y Valladolid, tenían un cura cada una. Por su parte, la población indígena era administrada mayormente por frailes franciscanos a quienes el conquistador Francisco Montejo les encargó su evangelización, una vez fundada Mérida en 1542. Ante la carencia de clérigos que pudiesen reforzar a la Iglesia diocesana, el obispo Toral solicitó al rey el envío de más franciscanos para ampliar el trabajo doctrinal entre los indios, ${ }^{18}$ ya que por entonces era difícil la formación local de clérigos.

En 1565 el obispo Toral viajó a México para asistir al Segundo Concilio Provincial que tuvo como propósito central jurar los decretos del Concilio de Trento. Uno de ellos fue la creación de un seminario en cada diócesis para la formación de clérigos, como ya se mencionó, cuya dotación debía provenir de las rentas eclesiásticas de cada obispado. ${ }^{19}$ Pero en el incipiente obispado de Yucatán sus ingresos eran muy escasos. De acuerdo con el mismo obispo, los diezmos apenas sumaban 700 pesos de minas (1158 pesos de oro común), ${ }^{20}$ por lo que, en una misiva al rey de 5 de abril de 1569, señaló que: "En este obispado, por la pobreza que hay de él, no se ha podido hacer el seminario tridentino, y hay de él muy gran necesidad por los muchos hijos de los vecinos españoles que se han procreado en esta tierra y, por falta de maestros y estudio, no se ejercitan en las letras". ${ }^{21}$

Por ello, el prelado pidió que de la Real Hacienda se fundara una cátedra de casos de conciencia y así conservar al maestro que llevó de la Universidad de México, el licenciado Cristóbal Vadillo. Pero en 1571 el obispo

${ }^{18}$ Carta del obispo al rey de 17 de octubre de 1565, Archivo Histórico Nacional, Diversos-Colecciones (en adelante AHN, DC), 24, N.73.

${ }^{19}$ Leticia Pérez Puente, Enrique González González y Rodolfo Aguirre Salvador, "Los concilios provinciales mexicanos primero y segundo", 17-40.

${ }^{20}$ Carta del obispo al rey de 17 de octubre de 1565, AHN, DC, 24, N.73.

${ }^{21}$ Archivo General de Indias, Audiencia de México (en adelante AGI, AM), 367, f. 138-139, citado en: Stella María González Cicero, Perspectiva religiosa en Yucatán, 1517-1571: Yucatán, los franciscanos y el primer obispo fray Francisco del Toral (México: El Colegio de México, 1978), 240-242. 
murió y en 1575 el licenciado Vadillo fue promovido al arcedianato de Michoacán. ${ }^{22}$

En 1576 el procurador del ayuntamiento de Mérida, Martín de Palomar, solicitó a la Corona promover un estudio de gramática latina para los españoles que sabían ya la lengua de los indios y “...teniendo quien les muestre latinidad, los que tomasen orden clerical y religiosa, harán gran fruto a la doctrina, conversión y catecismo de los indios...” Tampoco veía como única opción que los hijos fueran a estudiar a otras ciudades “...por ser los vecinos tan pobres como son, no tienen posibilidad de enviar a sus hijos a estudiar fuera de estas provincias..... ${ }^{23}$ Pero esta petición no prosperó. En cambio, el obispo fray Diego de Landa, (1572-1579), antiguo provincial de los franciscanos en Yucatán, impulsó el arribo de más franciscanos. ${ }^{24}$

Hasta fines del siglo XVI, el obispo fray Juan Izquierdo (1590-1602) estableció un estudio de Gramática en la catedral, para lo cual llevó de México al preceptor Melchor Téllez. El prelado explicó al rey que ello fue necesario para que los muchachos de la tierra se pudieran dedicar al estudio, a que muchos de ellos se habían aplicado y a que otros tuvieron que ir a México a cursar facultades mayores. Es clara la idea de terminar con la dependencia de estudios de la capital novohispana, por un lado, y disponer de docentes subordinados a la mitra, por el otro. El obispo también manifestó estar “...muy atajado por no tener que darles de comer ni en qué ocuparlos respecto de tener los frailes franciscanos todos los beneficios de la tierra...”, de ahí que el rey debía traspasar la tercera parte de las guardianías-conventos de los frailes al clero secular, advirtiendo que “...si esto no se hace, no hay para qué haber estudio de aquí en adelante, ni el obispo tiene necesidad de hacer más órdenes...." ${ }^{25}$ No obstante, esta secularización

${ }^{22}$ El licenciado Cristóbal Vadillo, antiguo catedrático de decretos en la Universidad de México, fue llevado a Mérida por el obispo Toral como provisor general y maestrescuela, cargo que le pidió al rey que ratificara en 1569, en AGI, AM, 211, N. 5, y AGI, AM, 367, f. 143. En este último documento le solicita al monarca que le otorgue un salario para que también lea cánones. En 1575 se buscó su reemplazo a la maestrescolía de Yucatán por haber sido promovido al arcedianato de la catedral de Michoacán, en AGI, Indiferente General (en adelante $I G), 738$, N. 153.

${ }^{23}$ AGI, Patronato Real (en adelante PR), 182, R.51, f. 18-18v. Martín Palomar se convertiría unas décadas después en el mecenas para fundar el colegio de Mérida como se verá más adelante.

${ }^{24}$ Durante el siglo xvi, la provincia franciscana de San José estuvo conformada principalmente por remesas de frailes españoles y, en menor medida, de Nueva España. La minoría tomó el hábito en Yucatán. Adriana Rocher Salas, “Clero y élites en Yucatán”, 35.

${ }^{25}$ Carta del obispo Izquierdo al rey de 1 de abril de 1598, AGI, AM, 369. 
fue rechazada en Madrid. Cabe hacer notar la vinculación que el obispo hizo entre la secularización de doctrinas y la formación de clérigos nativos, apuntando ya un proyecto a largo plazo. Al respecto, a fines del siglo XVI, el clero secular contaba solamente con 12 parroquias, 7 en la provincia de Yucatán y 5 en Tabasco. En comparación, los franciscanos tenían 24 guardianías y conventos. ${ }^{26}$ Sin embargo, la proporción de "almas en confesión" era sumamente desigual, pues mientras los frailes administraban a 130000 indios, los clérigos sólo a $17000 .^{27}$

La inquietud por fortalecer la base clerical local pronto se manifestó mediante nuevas iniciativas. La idea de secularizar doctrinas fue continuada por un clérigo local: el bachiller Pedro Sánchez de Aguilar, cura de Valladolid, graduado en Artes y Cánones en México, ${ }^{28}$ quien fue enviado a España por su obispo como procurador de negocios de la diócesis ${ }^{29}$ y para solicitar el traspaso de 10 doctrinas franciscanas. Su argumento fue que esos partidos pertenecían al clero secular, pero que el obispo Landa se las había quitado en 1573 para darlas a los religiosos. ${ }^{30}$ Sánchez de Aguilar aprovechó su estancia en España para graduarse de doctor en Cánones en la Universidad de Osma de Burgos en 1602. Al año siguiente, Sánchez insistió en una carta al rey sobre la problemática formativa de clérigos en Yucatán:

Hay alguna falta de clérigos y que esto se supliera con que se fundara algún estudio donde se leyera alguna lección de artes, teología, cánones o sagrada escritura a que son inclinados y aplicados los naturales y, por no leerse, todos los estudiantes en sabiendo latinidad luego se van a la Universidad de la ciudad de México de donde

${ }^{26}$ Cartas del obispo Izquierdo al rey de 1 de abril de 1598 y 15 de junio de 1599, AGI, AM, 369. Los beneficiados seculares eran 13 debido a que en Valladolid había dos curas.

${ }^{27}$ Se trata de un documento de 1601: Real Academia de la Historia, Colección Papeles Jesuitas, 156, f. 130-132, en Francisco de Solano y Pérez Lila, "La población indígena de Yucatán durante la primera mitad del siglo xviı", Anuario de Estudios Americanos, xxviII (1971): 188-190; véase María Cristina García Bernal, Yucatán. Población y encomienda bajo los Austrias (Sevilla: Consejo Superior de Investigaciones Científicas, Escuela de Estudios Hispano-Americanos de Sevilla, 1978), 80.

${ }_{28}$ Para noticias de Pedro Sánchez de Aguilar, véase cartas del obispo al rey de 15 de junio de 1599 y 12 de diciembre de 1605, AGI, AM, 369.

${ }^{29}$ AGI, Contratación, 5271, n. 9, f. 2.

${ }^{30}$ Rocher Salas, "Clero y élites en Yucatán”, 602; Adriana Rocher Salas, "La política eclesiástica regia y sus efectos en la diócesis de Yucatán”, Revista Complutense de Historia de América 30 (2004): 53-76. En este último artículo Adriana Rocher desarrolla un análisis de la secularización de las doctrinas en Yucatán y el papel que desempeñó Pedro Sánchez de Aguilar. 
nunca se vuelven respecto de hallarse bien en ella y entrar muchos en religión en que recibe notable daño ese obispado. ${ }^{31}$

Estas líneas son interesantes, no solamente porque prueban la consigna del clero local por lograr el apoyo real para fundar un estudio general de facultades, sino también porque señala una problemática poco visible en la historiografía: la migración de clérigos al centro de la Nueva España, como consecuencia de la falta de beneficios eclesiásticos en Yucatán. En respuesta, el rey, en cédula de 19 de abril de 1605, pidió mayores informes a las autoridades de Yucatán. El obispo Diego Vázquez de Mercado sugirió que con el reciente arribo de los jesuitas a Mérida se podría fundar un colegio a cargo de ellos, para lo cual se podrían asignar dos mil pesos de tributos de encomiendas. ${ }^{32}$ Pero esta petición no obtuvo respuesta de la Corona. Lo usual era que los fondos para fundar ese tipo de colegios provinieran de particulares, ya que el rey raramente otorgaba recursos para la fundación de estudios. ${ }^{33}$ En 1607 Vázquez de Mercado volvió a escribir a Madrid lamentando que los jesuitas se hubieran ido de Mérida por falta de la licencia real para residir, pero igualmente se quejó de la falta de clérigos por no haber estudios mayores en Mérida, insistiendo en la creación del colegio jesuita. ${ }^{34}$

Afortunadamente para el proyecto de clero secular, y sin haber aún una respuesta de Madrid, en 1609 el capitán Martín de Palomar ofreció dotar al colegio, pidiendo "...cuatro o seis religiosos sacerdotes que [...] lean gramática y casos de conciencia [...] y tengan estudio abierto para todos los hijos de vecinos de Yucatán, gratis...”. En 1611, enfermo y sin noticias aún del permiso real para fundar, Palomar dictó su testamento refrendando la dotación prometida. Pidió además que, en el ínterin de la fundación, se pusieran a censo los 26000 pesos que ofreció y se rentaran las casas para sustentar diversas obras pías, entre ellas la ayuda para "...algunos hijos de vecinos de esta provincia, pobres, que quieran ir a la universidad de México...”, con la condición de que juraran volver a Yucatán para la administración

${ }^{31}$ AGI, AM, 1064, L. 4, f. 8v-9v. Texto inserto en cédula real de 19 de abril de 1605 dirigida por separado al obispo de Yucatán, al gobernador de la provincia y al cabildo seglar de la ciudad de Mérida. Si bien no se señala la fecha de la carta de Pedro Sánchez de Aguilar al rey, ésta fue después de ser titulado como doctor, ya que así se refiere la respuesta del rey.

${ }^{32}$ Carta del obispo al rey de 12 de diciembre de 1605, AGI, AM, 369.

${ }_{33}$ Pilar Gonzalbo Aizpuru, Historia de la educación en la época colonial. La educación de los criollos y la vida urbana (México: El Colegio de México, 1990), 159-195.

${ }^{34}$ Carta del obispo al rey de 15 de julio de 1607, AGI, AM, 369. 
espiritual de los indios. La dotación de Palomar y las gestiones realizadas por el procurador de los jesuitas, Francisco de Figueroa, dieron buenos resultados. El rey, por cédula de 16 de julio de 1611, otorgó su licencia para la fundación del colegio de Mérida donde se enseñaría Latín, Artes y Teología. ${ }^{35}$ Sin embargo, la apertura se efectuó unos años más tarde, en 1618. Durante el acto inaugural se constató que había un “...estudio de gramática con copia de estudiantes [...] con sus libros en las manos, hijos de los vecinos principales de esta ciudad, y el padre lector Melchor Maldonado leyéndoles gramática...” ${ }^{36}$ De acuerdo con lo previsto, se comenzaron a leer las cátedras de Gramática y Casos de Conciencia o Moral, necesaria para el ministerio de la confesión.

Paralelamente, en Madrid, los jesuitas tramitaban que sus colegios en las Indias pudieran conceder grados académicos. En consulta al rey de 31 de agosto de 1612, el Consejo de Indias informó que la Compañía gozaba de privilegio apostólico para graduar en Artes y Teología en sus colegios y en provincias donde no hubiese universidades, como ya se usaba en varias partes de Europa, privilegio que sería de mucho beneficio en América, “...por no haber en ellas más de dos universidades, de las cuales están muy apartados muchos colegios de la Compañía como son en el Perú, los de Chile, Tucumán y Nuevo Reino de Granada [...] los de las Islas Filipinas". ${ }^{37}$ No mencionó a Yucatán muy probablemente porque todavía no se había abierto el colegio jesuita en esta provincia. El procurador de los jesuitas también aludió a que por la distancia, los estudiantes no podían acudir a las universidades y, por faltarles el premio de los grados, no se animaban a continuar estudiando; de ahí su solicitud para que pudieran graduarse en Artes y Teología, por mano de los maestrescuelas de las catedrales respectivas.

Finalmente, en 1617 el rey ordenó a su embajador en Roma, el cardenal Gaspar de Borja, “...supliquéis a su santidad tenga por bien de conceder a los colegios de la Compañía de Jesús...” pudieran dar los grados por el tiempo que a él le pareciera convenir. Un breve papal fue otorgado el 8 de

${ }^{35}$ Un análisis sobre Martín de Palomar y las condiciones que llevaron a la fundación del colegio, en Rafael Patrón Sarti y Enrique González González, "El capitán Martín de Palomar, regidor, encomendero y benefactor: su testamento (Mérida, Yucatán, 1611)”, Estudios de Historia Novohispana, 43 (2010): 185-252.

${ }^{36}$ Archivo General de la Nación (en adelante AGN), Indiferente Virreinal (en adelante IV), 1260, exp. 15, f. $44-45$.

37 Guillermo Hernández de Alba, Documentos para la historia de la educación en Colombia. Tomo 1, 1540-1653 (Bogotá: Patronato Colombiano de Artes y Ciencias, 1969), 128-130. 
agosto de 1621 por Gregorio XV, en el que se dispuso como limitantes a esos colegios que sólo pudieran graduar “...adonde no hubiere universidades de estudios generales y estuvieren distantes de las universidades públicas doscientas millas..." y que los grados fueran otorgados por los obispos o los capitulares en sede vacante "...por tiempo de diez años...". Con estos acotamientos aceptados, el rey otorgó pase al breve papal en 1622. Los permisos llegaron a Mérida y fueron aceptados por las autoridades civiles y eclesiásticas en noviembre de 1624. El obispo y el cabildo eclesiástico decretaron su cumplimiento y la fundación de "...la dicha universidad en el colegio de la santa Compañía de Jesús en esta ciudad". ${ }^{38}$

La nueva categoría otorgada al colegio animó a las autoridades de Yucatán a solicitar al rey una mejor dotación económica, logrando 500 ducados para la lectura de las cátedras de Gramática y Casos de Conciencia, aunque sólo por diez años, como había estipulado el breve papal mencionado antes. Pasado este tiempo la universidad cerró sus puertas, ya sea por la falta de recursos, por cesar la licencia real o por ambas causas. Sólo en 1646 el rey restableció la dotación y, a partir de 1648, se volvieron a otorgar grados en Artes y Teología, ya sin prescripción de tiempo. ${ }^{39}$

Según las constituciones de la nueva Universidad de Mérida, basadas en su similar de Santafé de Bogotá, para obtener el grado de bachiller en Artes se requerían dos cursos con materias de Súmulas, Lógica y Física; mientras que para el de bachiller en Teología se pedirían, además del título de bachiller en Artes, haber “...oído cuatro cursos de teología [...] con dos lecciones de escolástico cada día y una de escritura o moral”. ${ }^{40}$ En informaciones de 1627 se describió que había "...lecturas de gramática, humanidad, filosofía y teología moral y escolástica...." ${ }^{41}$ Sin embargo, con la interrupción de los grados en 1634, quedaron por entonces solamente las

${ }^{38}$ Rafael Patrón Sarti, ed., La Universidad de Mérida de Yucatán. Relación de los actos y fiestas de fundación en 1624 (Mérida: Ediciones de la Universidad Autónoma de Yucatán, 2013), 23-26, 32-35 y 105-110.

${ }^{39}$ Rafael Patrón Sarti, "La Universidad de Mérida de Yucatán en la época colonial: documentos probatorios de su existencia”, Historias, 80 (2011): 53-55.

${ }^{40}$ En Archivum Romanum Societatis Iesu, Nuevo Reino y Quito, 17, Fórmula de graduar. Incisos §5 y §19.

${ }^{41}$ El padre Juan Acacio, "rector del colegio de la Compañía de Jesús de esta çiudad de Mérida y de la Vniversidad en él fundada", dio la noticia de los graduados el 13 de noviembre de 1627, en AGN, IV, 5446, exp. 6, f. 1-1v. En el f. 9 del mismo expediente, se detallaron las cátedras leídas. 
cátedras de Gramática y Moral. ${ }^{42}$ En 1648 se reanudó la concesión de grados reabriéndose las cátedras cerradas. ${ }^{43}$ En 1659, el cabildo eclesiástico informó al rey que la ciudad y obispado ya contaba con clérigos preparados gracias a “...las lecciones de gramática y filosofía y teología moral y escolástica que se lee en el colegio...”. ${ }^{44}$ En 1671, se informó que en Mérida había 6 jesuitas (4 de ellos sacerdotes y dos legos) “...tres de los cuales son lectores de teología, filosofía y gramática...”, uno en cada cátedra.$^{45}$ La segunda mitad del siglo XVII fue entonces una etapa de consolidación del colegio universidad, impulsada por el clero secular, los jesuitas y la diócesis de Yucatán.

Fue a comienzos del siglo xvin que la universidad recibió nuevos apoyos, en un contexto de ascenso del clero secular parroquial, gracias al gran impulso de la estructura parroquial por las secularizaciones de $1679 .{ }^{46} \mathrm{En}$ 1700, el bachiller Gaspar Güemes escrituró una dotación para fundar el colegio convictorio de San Pedro ${ }^{47}$ con siete alumnos becarios y “...dos sujetos sacerdotes de dicha sagrada religión de la Compañía y que juntamente leyesen en esta universidad, uno la cátedra de teología moral y el otro la clase de mínimos y menores..... La dotación sería de 26000 pesos: 15000 para los catedráticos y 11000 para los becarios. ${ }^{48}$ De esta manera, los lectores aumentaron a cinco docentes: “...dos teología, dos gramática y uno filosofía.... ${ }^{49}$ Los nuevos maestros debían residir en el convictorio para su cuidado y doctrina, conforme a la petición del fundador y la licencia real de fundación otorgada en $1711 .{ }^{50}$

${ }^{42}$ Archivo Histórico de la Provincia Mexicana de la Compañía de Jesús (en adelante AHPMCJ), Catálogos de la provincia de México, años 1626 y 1638.

${ }^{43}$ Sobre los problemas económicos del colegio y el cierre temporal de la universidad, véase Patrón Sarti, “La Universidad de Mérida”, 53-54.

${ }^{44}$ Carta del cabildo eclesiástico al rey de 14 de enero de 1659, AGN, Jesuitas (en adelante $J$ ), I-32, exp. 2, f. 20v.

${ }^{45}$ AнpмCJ, Catálogos de la provincia de México, año 1671.

${ }^{46}$ Medina Suárez, "La consolidación del clero secular".

${ }^{47}$ Este colegio funcionó más como una residencia para estudiantes que arribaban fuera de Mérida. Las clases las tomaban cruzando la calle en el colegio-universidad.

${ }^{48}$ AGN, IV, 933, exp. 26.

${ }^{49}$ AHPMCJ, Catálogos de la provincia de México, año 1708.

${ }^{50}$ En la carta del gobernador Cristóbal de Zayas al conde de Aranda de 16 de agosto de 1767 le narró que los dos padres jesuitas "del citado seminario [de San Pedro] pasaban al colegio en donde estaban las aulas a dar las lecciones", Archivo Nacional de Chile, Jesuitas de América, v. 280, f. 4v. Véase Rafael Patrón Sarti, La licencia real de fundación del colegio seminario de San Pedro en Mérida de Yucatán, 1711 (Mérida: Ediciones de la Universidad Autónoma de Yucatán, 2014), p. 17. 
En 1762 el colegio universidad adquirió un nuevo perfil de estudios al abrirse la cátedra de Cánones, leída inicialmente por Francisco Javier Alegre. ${ }^{51}$ En 1766 los jesuitas certificaron que se leían seis cátedras: Latinidad, Retórica, Filosofía, Casos de Conciencia, Cánones y Teología escolástica. ${ }^{52}$ Hubo también cátedra de Leyes a partir de $1765 .{ }^{53}$ Sin embargo, no contaba con el permiso real. Por ello, el ayuntamiento de Mérida ofreció dotarla y solicitó el permiso al rey. Pero la respuesta fue negativa, por lo que en agosto de 1766 se declaró nula. ${ }^{54}$

Este tropiezo pronto se empequeñeció ante la expulsión de los jesuitas en 1767 y el cierre de todos sus colegios, afectando a todos los clérigos que ahí se formaban. Pero también la validez de sus grados fue cuestionada, como sucedió cuando el fiscal de la audiencia de Guatemala objetó el de bachiller en Cánones de Estanislao del Puerto, graduado en Mérida, quien

${ }^{51}$ En 1761 se estaba discutiendo qué maestro iría a leer cánones a Mérida, señalándose al padre Thomas Butler como muy a propósito para el caso, por lo que el padre Alegre, quien fue al final el elegido, podría haber comenzado su curso hacia 1762. Véase Miguel Valle Pimentel, “Agustín Pablo de Castro, 1728-1790. Vida y semblanza" (tesis de maestría en Letras Españolas, Universidad Iberoamericana, México, 1962), nota 9, 66. El jesuita veracruzano Francisco Xavier Alegre (1729-1788) fue maestro de gramática, retórica, filosofía y derecho canónico. La historiadora Alicia Mayer resume que Alegre “destacó por su gran erudición en antigüedad clásica, filosofía escolástica y moderna y además en ciencias. Conoció con profundidad el griego, el latín, el italiano, el francés, el náhuatl y el inglés". La misma autora comenta que guio la Academia de Humanidades y Bellas Letras en San Ildefonso de México y que escribió diversas obras como la Historia de la Provincia de la Compañía de Jesús de Nueva España, Arte poética de Boileau, Institutionum theologicarum y otros trabajos de retórica, geometría, poesía y sermones. Es considerado uno de los principales intelectuales novohispanos de mediados del siglo xviII. Véase Alicia Mayer, "Modernidad y tradición, ciencia y teología. Francisco Javier Alegre y las Institutionum theologicarum", Estudios de Historia Novohispana, 47 (2012): 97-102.

52 Archivo Histórico del Arzobispado de Yucatán (en adelante AHAY), Oficios y Decretos, v. 1. Este archivo fue cambiado de sede y se modificó su clasificación, pero existe una guía para localizar los documentos con base en la clasificación anterior, mucha de la cual se usó en el transcurso de este trabajo.

53 AGN, IV, 5800, exp. 49, f. 7v. El padre Agustín Pablo de Castro, quien era catedrático de cánones, en medio de la disputa por la falta de permisos de las cátedras jurídicas escribió unos apuntes sumamente críticos sobre la universidad de Mérida desde sus inicios hasta 1765 y señaló que "se ha dado passo a la fundación de Leyes". Los apuntes abarcan los folios 3-8v. En el Анрмсл, саја 36, 1431, se encuentra lo que parecen ser tres borradores del mismo y que no estuvieron disponibles para investigadores externos hasta hace pocos años. Los bosquejos en el Aнрмсл fueron citados en 1962 por Valle Pimentel, "Agustín Pablo de Castro", 166-167, y González González, El poder de las letras, 344-345 (y un extracto de los apuntes en 601-602). Este último autor resumió algunas de las críticas del padre Castro.

${ }^{54}$ AGN, J, II-36, exp. 211, f. 309-310. 
había solicitado su examen para abogado. La disputa llegó a Madrid y el rey, en carta de 19 de octubre de 1768, secundó al bachiller del Puerto, ${ }^{55}$ pero también estipuló que en adelante aceptara solamente graduados de universidades vigentes.

Una nueva universidad se daría hasta después de la consumación de la independencia de México. El 18 de marzo de 1824 el Congreso de Yucatán dispuso que el Seminario Tridentino de San Ildefonso fuese su sede y autorizó al obispo Pedro Agustín Estévez encabezar el proceso. Este prelado fungió también como el cancelario de la universidad y nombró a ocho doctores fundadores y un rector. Finalmente, se señaló el 12 de diciembre de 1824 para la instalación formal de la Universidad Literaria de Mérida. ${ }^{56}$

Respecto de la población estudiantil, la del colegio de Mérida, aunque no es comparable con la de otros similares del centro de Nueva España, su importancia reside en dos aspectos: uno, significaba el triunfo de poder formar localmente un clero secular, a pesar de tantos obstáculos y limitaciones de la Iglesia diocesana, y dos, reforzaba a la elite dominante hispánica de la península, al permitir su presencia en las instituciones eclesiásticas del obispado. ${ }^{57}$

En los cursos en 1624 se matricularon 36 estudiantes, clérigos y seglares, de los cuales 16 se graduaron de bachilleres en Artes en 1627. Uno de ellos fue el bachiller Francisco de Cárdenas Valencia quien, en una relación

55 Patrón Sarti, "La Universidad de Mérida", 59-61. La problemática para el título de abogado a Estanislao del Puerto y la respuesta del real, en: John Tate Lanning, Reales cédulas de la Real y Pontificia Universidad de San Carlos de Guatemala (Guatemala: Editorial Universitaria de la Universidad San Carlos de Guatemala, 1954), 185-187.

${ }^{56}$ Después de la muerte del obispo Estévez, el doctor José María Guerra se convirtió en 1834 en el primer yucateco en acceder a la mitra de Yucatán. Véase Crescencio Carrillo y Ancona, El obispado de Yucatán. Historia de su fundación y de sus obispos desde el siglo XVI hasta el XIX (Mérida: Imprenta y Litografía R. Caballero. Reedición Fondo Editorial de Yucatán, 1979), t. II, 976-979 y 989. Para la refundación de la Universidad de Mérida se utilizaron los artículos 23 y 40 del Reglamento General de Instrucción Pública decretado por las Cortes el 29 de junio de 1821. Sobre la fundación y la reglamentación de la universidad literaria de Mérida en el siglo Xıx, véanse los trabajos de Roger A. Domínguez Saldívar y Manuel Jesús Uc Sánchez, "Los proyectos de enseñanza superior en Yucatán durante la crisis del régimen colonial (1803-1824)”, en Historia de la educación superior en Yucatán: las instituciones (universidad, colegio e instituto), siglos XIX $y \mathrm{XX}$, coordinación de Jorge I. Castillo Canché, Roger A. Domínguez Saldívar y José. E. Serrano Catzim (Mérida: Universidad Autónoma de Yucatán, Facultad de Ciencias Antropológicas, 2017), 85-110; José E. Serrano Catzim y Jorge I. Castillo Canché, "La universidad literaria de Mérida a través de su reglamentación, 18241854", en Historia de la educación superior, 141-180.

${ }^{57}$ Medina Suárez, "La consolidación del clero secular”, 369. 
de méritos, notificó que “...estudió en el colegio de la Compañía de Jesús de la ciudad de Mérida y se graduó de bachiller en artes...." ${ }^{8}$ Aunque comenzó la facultad de Teología, no la terminó pues decidió abandonarla para buscar una parroquia. Este caso representa una constante en el devenir de la clerecía novohispana promedio, respecto del nivel de estudios universitarios alcanzado.

En el siglo XVIII la búsqueda de grados de bachiller por parte de la clerecía novohispana llegó a su apogeo..$^{59}$ Es probable que las instituciones eclesiásticas en ese siglo llegaran a su mayor crecimiento, provocando una demanda de títulos universitarios no vista hasta entonces. La formación académica del clero secular no hizo sino reforzarse en esa centuria. En el arzobispado de México, por ejemplo, a partir de 1713, con el arribo de José Lanciego Eguilaz, se revisaron los criterios para la ordenación sacerdotal y se hicieron cumplir con más rigor los requisitos exigidos en la normativa tridentina. ${ }^{60}$

En Yucatán no hubo excepción, luego de la secularización de doctrinas de 1679 y el proyecto del clero para reducir a los indios que aún vivían dispersos, lejos de los pueblos y al sur de la península, y administrarlos espiritualmente. Así lo demuestra el mandato del obispo Juan Gómez de Parada (1715-1728), quien visitó la diócesis entre 1719 y 1720 e informó Madrid que en su recorrido reformó todo lo que había podido y que respecto de su clerecía expulsó a clérigos “indignos”, aprobó personalmente a nuevos sacerdotes y clérigos ya en funciones, obligó a los alumnos a estudiar más y examinó a los opositores a curatos. ${ }^{61} \mathrm{El}$ obispo quiso así mejorar la disciplina de la clerecía y el desempeño de los curas, preocupación que por esos años se discutió mucho en Madrid, con repercusiones en Indias. ${ }^{62}$ Las nuevas constituciones sinodales establecieron exámenes públicos obligatorios para los nuevos ordenados, al igual que a curas y confesores, señalando

58 Patrón Sarti, ed., La Universidad de Mérida, 167. La noticia de los graduados en AGN, IV, 5446, exp. 6, f. 1-1v.

59 Taylor, Ministros de lo sagrado, v. I, 130, concluyó que “...la mayor parte [de los futuros curas párrocos] sólo completó el bachillerato en artes y se deslizó rápidamente hacia la teología moral y las lenguas indígenas previas a la ordenación...”.

${ }^{60}$ Aguirre Salvador, Un clero en transición, 58-70.

${ }^{61}$ Aguirre Salvador, "El sínodo de Yucatán para la reforma del clero: entre la política borbónica y los intereses regionales”, en Reformas y resistencias en la Iglesia novohispana, coordinación de María del Pilar Martínez López-Cano y Francisco Javier Cervantes Bello (México: Universidad Nacional Autónoma de México, Instituto de Investigaciones Históricas; Puebla: Benemérita Universidad Autónoma de Puebla, 2014), 251-284.

${ }^{62}$ Aguirre Salvador, Un clero en transición, 55-69. 
que incluso podrían negarse las órdenes sacerdotales y curatos a los aspirantes con deficiencias probadas. ${ }^{63}$ Para quienes quisieran ordenarse a título de administración de indios, se dispuso que deberían ir a servir también a los curatos rurales, pues todos buscaban quedarse en Mérida para su comodidad personal. ${ }^{64}$

En la segunda mitad del siglo XVIII se alcanzaron los mayores índices de clérigos graduados en Yucatán. De 91 opositores a curatos entre 1753 y 1780, $82 \%$ eran bachilleres en Artes y el 12\% alcanzó el grado de bachiller en Teología. El resto, 6\%, eran doctores en Teología. En Cánones se registraron sólo tres bachilleres, sobrevivientes de la única generación que pudo estudiar esa disciplina en 1765, antes del cierre de la universidad (véase el cuadro 1).

El valor utilitario de los grados se expresa también en que la gran mayoría sólo obtuvo el de bachiller en Artes. ${ }^{65}$ El escaso estudio de la Teología Escolástica por los clérigos de Yucatán fue manifestado al rey en una misiva de 1737 por el obispo fray Francisco Pablo Coronado:

No hay en esta diócesis eclesiásticos distinguidos por su literatura y es raro el que en la teología escolástica llega a la raya de la mediocridad [...] La facultad a que se aplican casi todos es la teología moral en el grado de sumistas, para cumplir en el ministerio pastoral a que únicamente aspiran, y en esta clase suelen aprovechar de modo que salen decentes para curas y ministros [...]. ${ }^{66}$

${ }^{63}$ Juan Gómez de Parada, Constituciones sinodales del obispado de Yucatán, transcripción, edición y notas de Gabriela Solís Robleda (Mérida: Universidad Nacional Autónoma de México, Centro Peninsular en Humanidades y Ciencias Sociales, 2008), título cuarto, sección primera, párrafo primero. En adelante todas las citas sobre el sínodo de Yucatán se refieren a esta edición.

${ }^{64}$ Título cuarto, sección segunda, párrafo tercero.

${ }^{65}$ A pesar de la omnipresencia del grado de bachiller en la clerecía yucateca en el siglo XVıII aún se permitieron clérigos sin algún título universitario. En 1762, Joseph Cristóbal de Vargas, sin grados académicos, fue aprobado en latinidad y materias morales por el doctor Pedro Mora y Rocha, rector del seminario tridentino de San Ildefonso, considerándolo apto para el sacerdocio y la confesión. Este caso indica que, excepcionalmente, aún se pasaba por alto la falta de grado académico si el clérigo demostraba buen conocimiento de aquellas materias imprescindibles para la administración de sacramentos. AHAY, Becas y Órdenes (en adelante $B y O)$, v. 6, exp. 328, f. 429.

${ }^{66}$ Carta del obispo al rey de 28 de julio de 1737, AGI, México, 3168. Parte de este párrafo en Adriana Rocher Salas, "Para lo divino y para lo humano: los colegios jesuitas de Yucatán”, en Espacios de saber, espacios de poder. Iglesias, universidades y colegios en Hispanoamérica, siglos XVI-XIX, coordinación de Rodolfo Aguirre Salvador (México: Universidad Nacional Autónoma de México, Instituto de Investigaciones sobre la Universidad y la Educación; México: Bonilla Artigas Editores; Madrid: Iberoamericana Vervuert Editorial, 2013), 274. 
Cuadro 1

GraduAdos UNIVERSITARIOS DE MÉrIDA

QUE OPOSITARON A CURATOS, 1753-1780

\begin{tabular}{lrr}
\hline BA & 75 & $82.4 \%$ \\
BA, BT & 3 & $3.3 \%$ \\
BA, MA & 2 & $2.2 \%$ \\
BA, BT, MA, DT & 5 & $5.5 \%$ \\
BA, BT, DT & 3 & $3.3 \%$ \\
BA, BC & 2 & $2.2 \%$ \\
BC & 1 & $1.1 \%$ \\
Total & 91 & $100.0 \%$ \\
\hline
\end{tabular}

BA = bachiller en Artes; $\mathrm{BT}=$ bachiller en Teología $;$ вС = bachiller en Cánones; MA = maestro en Artes, DT $=$ doctor en Teología.

Se consideraron quienes indicaron haber estudiado o graduado en Mérida.

FUENTE: AHAY, CaC, v. 1-7, exp. 1-21.

Cabe mencionar que los grados se daban por estudios en Teología Escolástica, no por la Moral. Esta última, sin embargo, era fundamental para la administración espiritual de las parroquias. Los exámenes para obtener las órdenes sacerdotales indican las materias en que eran auscultados los aspirantes. En 1762 el provisor del obispado solicitó al jesuita Andrés Prudencio de la Fuente, rector del Colegio Seminario de San Pedro, examinar “...en latinidad y materias morales...” al bachiller Cipriano Bencomo y Ruiz, estudiante teólogo, pues había solicitado letras dimisoriales para ordenarse de sacerdote en otro obispado, a título de administración de sacramentos en lengua maya. ${ }^{67}$

Las parroquias: principal destino de los clérigos con grados académicos

Si fue común en los obispados de Indias que las parroquias representaran un destino para muchos clérigos, este horizonte fue aún más importante en

${ }^{67}$ AHAY, ByO, v. 6, exp. 332, f. 461-470. Sobre los clérigos dedicados a la administración de sacramentos en las lenguas indígenas, véase el trabajo de Rodolfo Aguirre Salvador, "La demanda de clérigos lenguas en el arzobispado de México, 1700-1750”, Estudios de Historia Novohispana, 35 (2006): 47-70. 
obispados con un menor número de empleos eclesiásticos como Yucatán. De ahí que no resulte difícil comprender que en este obispado la competencia por las parroquias y la secularización de las doctrinas franciscanas hayan sido objetivos de primer orden para la clerecía de Yucatán en toda la era novohispana. Francisco de Cárdenas nació en Valladolid en 1605 y a los 13 años se mudó a Mérida para comenzar sus estudios mayores y graduarse de bachiller en Artes en 1627. También sirvió de acólito y sacristán menor en la catedral tomando las órdenes sacerdotales. Con ese único grado, Cárdenas comenzó muy pronto a opositar a curatos: en 1629 se opuso y ganó el de Sotuta y en 1638 ascendió al más pingüe de Yaxcabá, aumentando sus ingresos en 58\%. Este mismo año fue escogido para escribir la relación historial eclesiástica de Yucatán; buscó una prebenda en la catedral, pero sin éxito y al parecer murió en Yaxcabá. ${ }^{68}$ La trayectoria de Cárdenas representa un patrón que muchos de los clérigos bachilleres siguieron en Yucatán, especialmente aquellos sin grados mayores. Aunque fue común que luego de graduarse en Artes, los jóvenes comenzaran cursos de Teología, especialmente la Moral, muy pocos alcanzaban un grado en esta facultad, pues una vez ordenados de presbíteros abandonaban los estudios para buscar trabajo en las parroquias, como ya se ha mencionado. Usualmente se empleaban, en sus inicios, como tenientes de curas o ayudantes en las parroquias. Con el tiempo, los más afortunados llegaban a ser titulares de alguna parroquia y, si era de bajos ingresos, buscaban escalar a alguna otra de mayor renta.

El pleito comenzado por Pedro Sánchez de Aguilar a principios del siglo XVII, mencionado páginas antes, resultó en el traspaso de cuatro parroquias franciscanas al clero secular en 1602 y culminó hasta 1679 con la secularización de las otras 6 demandadas, mismas que comenzaron a ser subdivididas para crear nuevos partidos. ${ }^{69}$ De esa forma, a principios del siglo

${ }^{68}$ Eleanor B. Adams, "Note on the Life of Francisco de Cárdenas Valencia”, The Americas, v. 2, n. 1 (1945), 21-29; AGI, $A M$, 238, N. 7; AGI, PR, 86, N. 3, R. 1; AHN, DC, 26, N. 88. El curato de Yaxcabá tenía un ingreso anual de 1400 pesos mientras que el de Sotuta 885 pesos. Véase Francisco de Cárdenas Valencia, Relación historial eclesiástica de la Provincia de Yucatán en la Nueva España, escrita el año de 1639 (México: Antigua Librería Robredo de José Porrúa e Hijos, 1937), 100-101. Esta obra escrita por el bachiller Cárdenas Valencia en 1639 fue publicada casi tres siglos después, en 1937. Su trabajo constituye una de las principales fuentes para la historia de la Iglesia secular del Yucatán colonial. El que haya sido escogido para escribirla, sugiere que tuvo una cierta capacidad en letras, mucha adquirida en su paso por la Universidad de Mérida; las relaciones que pudo haber desarrollado con las autoridades durante su estancia en la capital yucateca y méritos acumulados durante su carrera eclesiástica.

${ }^{69}$ Rocher Salas, "La política eclesiástica regia”, 66-71. En 1602 fueron traspasadas al clero secular las doctrinas de Ichmul, Hocabá, Tixcocob y Tixchel, y en 1680, las de Tizimín, 
XVIII, los clérigos administraban 26 curatos, que representaban a $40 \%$ de la población indígena. ${ }^{70}$ En comparación, la provincia franciscana de San José de Yucatán estaba constituida por 31 conventos, 30 cabeceras de doctrina con sus respectivos pueblos de visita y cerca de 200 frailes. ${ }^{71}$ Esta situación cambió cuando, entre 1754 y 1757, otras diez doctrinas fueron transferidas al clero secular, entre ellas aquellas con altos números de población española como fueron las de Mérida, Campeche y Valladolid. ${ }^{72}$ Con todo ello, las parroquias aumentaron a 40 en 1734 y a 58 en 1765 . A su vez, el número de presbíteros seculares aumentó de 60 en 1643 a 168 en 1734, aunque no todos con empleo fijo. En este último año, casi la mitad de los sacerdotes trabajaba en parroquias rurales y el resto habitaba en los principales centros de población española: en Mérida 63, en Campeche 17 y en Valladolid 8, sirviendo muchos en sus iglesias, ermitas y capillas. Aquellos sin ocupación fija estaban listos para acudir a los pueblos para sustituir a los clérigos seculares que faltaban por enfermedad, mortandad o alguna otra causa. ${ }^{73}$

Respecto del porcentaje de clérigos bachilleres en las parroquias fue de menos a más con el paso de las décadas. En 1599, por ejemplo, de los 13 beneficios en Yucatán y Tabasco, tres fueron ocupados por bachilleres (23\%), dos de ellos graduados en México y otro en Salamanca (véase la gráfica 1). Con la apertura de la universidad, sus graduados comenzaron a ocupar curatos. En 1643, el 35\% de los curas beneficiados eran graduados (siete bachilleres y un licenciado). En 1668, por primera vez los curas ba-

Homún, Umán, Hunucmá, Hecelchakán, Champotón y las derivadas de Calotmul, Sahcabchén, Mamá y Tecoh.

${ }^{70}$ Rocher Salas, "Las doctrinas de indios", 87.

${ }^{71}$ Adriana Rocher Salas, La disputa por las almas. Las órdenes religiosas en Campeche, siglo XVIII (México: Consejo Nacional para la Cultura y las Artes, 2010), 109.

${ }^{72}$ AHAY, CaC, v. 2, exp. 7, y v. 3, exp. 11, para las colaciones de los curatos a clérigos seculares.

${ }^{73}$ Los datos para 1643 y 1734 en Memorial de la clerecía de 8 de marzo de 1643, AGI, AM, 369, y carta del obispo al rey de 28 de julio de 1737, AGI, AM, 3168. El dato de 1765 es un cálculo propio basado en información obtenida de AHAY, CaC, v. 1-7. Los capellanes de misa con grados universitarios fueron alrededor de la mitad al momento de la colación, aunque algunos continuaban estudiando hasta graduarse, pero otros pudieron quedarse sirviendo sus capellanías sin molestarse por más estudios o por trabajar en las parroquias. Para los datos de capellanes graduados, véase a Luis Raúl Ortiz Rubio, "En resguardo de los bienes y el alma. La fundación de capellanías en Yucatán durante los siglos XVII y XVIII” (tesis de maestría en Historia, Centro de Investigaciones y Estudios Superiores en Antropología Social, Mérida, 2016), 123-130. En el caso de confesores, datos encontrados en el archivo eclesiástico no son lo suficientemente confiables para concluir sobre sus grados universitarios. 
Gráfica 1

PORCENTAJE DE CURAS CON GRADOS ACADÉMICOS, 1599-1815

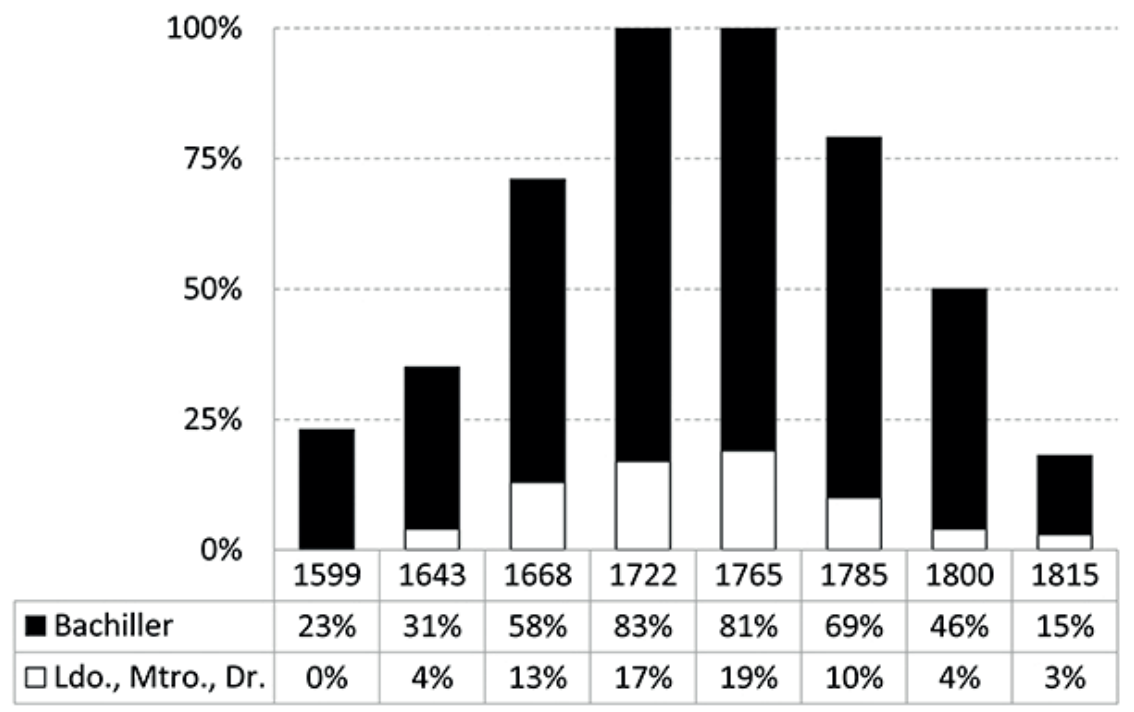

Fuentes: Carta del obispo Izquierdo al rey de 15 de junio de 1599 y Memorial de la clerecía de 8 de marzo de 1643, AGI, AM, 369; Carta de la clerecía de Yucatán al rey de 26 de julio de 1668, AGI, AM, 361, R.5, N.69; Gómez de Parada, Constituciones, 265-268; Carta del clero de Yucatán al rey de 5 de noviembre de 1785, AGI, AM, 2599; Base de datos obtenida de AHAY, CaC, v. 1-23.

NotA: para algunos años se refiere sólo a los títulos que ostentaban o no en las relaciones y, cuando fue posible, se verificó y corrigió con datos de sus informes de méritos.

chilleres e incluso algunos doctores fueron mayoría (71\%). ${ }^{74}$ Los grados se habían ya convertido en un mérito eclesiástico que acabó predominando, aun antes de la secularización de doctrinas de 1679.

Ya en el siglo XVIII, especialmente entre 1722 y 1765, la gran mayoría de los curas tenía algún grado académico. Sin embargo, con la clausura de la universidad en 1767, el número de graduados en los curatos disminuyó: en 1785 fue el $79 \%$, a principios del siglo xix fue el 50\% y para 1815 ya sólo el $18 \% .{ }^{75}$ Es indudable que las nuevas generaciones de curas de Yuca-

${ }^{74}$ AGI, AM, 361, R. 5, N. 69. Es un documento signado por la clerecía de Yucatán sin detallar las parroquias. El 58\% de los clérigos firma como bachiller.

${ }^{75}$ El resto de los opositores no reportaron tener grado ni en concurso a curatos ni cuando eran elegidos en las ternas y elegidos para un curato. Sólo mencionaban que habían hecho estudios, la mayoría en el Seminario Tridentino de Mérida, donde no se daban grados. 
tán, a principios del siglo xIX, tuvieron que ser aceptados sin poseer grados de bachiller.

En la gráfica 2 se observan curatos que fueron servidos por clérigos bachilleres, entre 1752 y 1780 , y la renta aproximada que obtenían, tanto en los rurales como en los urbanos. Se han incluido algunas sacristías a manera de comparación. Si bien no se tuvieron los ingresos para todos esos años, y fueron calculados según las mesadas eclesiásticas ${ }^{76}$ que los curas pagaban a la real hacienda, los datos sirven para dar un orden de magnitud. Puede observarse que si bien algunos bachilleres sirvieron largos tiempos en curatos de ciudades españolas, como el de catedral o el de Santiago, de Mérida, la mayoría se desempeñó en parroquias rurales de indios. Así, los bachilleres pasaron el $85 \%$ de sus años de servicio en estos espacios y solo el $15 \%$ en curatos urbanos (véase el cuadro 2). ${ }^{77}$

La renta promedio fue de 1230 pesos anuales, aunque varió considerablemente entre las parroquias: desde los escasos 250 pesos de Chicbul hasta los 3400 de Umán (véanse la gráfica 2 y el cuadro 3). Estos ingresos no fueron netos para los titulares ya que, en curatos extensos se contrataba a auxiliares, además de que todos tenían otros gastos, como fueron aquellos en ornamentos y mantenimiento de la iglesia. Algunos párrocos complementaron sus ingresos con otras actividades como las estancias y las haciendas de ganado y producción de miel. ${ }^{78}$

Pero un sector minoritario de curas con grados de licenciado, maestro o doctor, también buscaron en las parroquias un destino eclesiástico, ya sea temporal o de por vida. En 1643, sólo uno de los 22 curas tuvo un grado mayor (véase la gráfica 1). En 1722 el porcentaje de curas con grado mayor aumentó a 17\%, todos educados en Mérida, proporción que aumentó a 19\% en 1765. Estos porcentajes se asemejan a los reportados, algunas décadas más tarde, en las diócesis de Guadalajara, 16\% en 1790, y en la de México, $17 \%$ en $1793 .{ }^{79}$ Pero en Yucatán, con el cierre de su universidad, los números empezaron a decaer. En 1785 el porcentaje fue 10\% y, al empezar el

${ }^{76}$ La mesada eclesiástica era un gravamen que todo nuevo beneficiado eclesiástico debía pagar a la Real Hacienda y consistía en un mes de salario. Manuel Teruel Gregorio de Tejada, Vocabulario básico de la historia de la Iglesia (Madrid: Crítica, 1993), 29.

${ }^{77}$ Los curatos definidos como urbanos fueron aquellos intra y extratramuros de los principales centros de españoles de la época: Mérida, Campeche y Valladolid.

78 Robert W. Patch, Maya and Spaniard in Yucatan, 1642-1812 (Stanford: Stanford University, 1994), 111; Laura Machuca Gallegos, Los hacendados de Yucatán 1785-1847 (México: Centro de Investigaciones y Estudios Superiores en Antropología Social, 2011), 133-162.

79 Taylor, Ministros de lo sagrado, 125. 
Cuadro 2

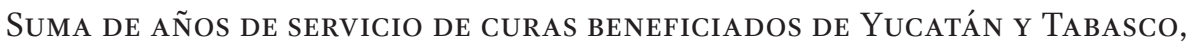
SEGÚN GRADOS UNIVERSITARIOS Y TIPO DE PARROQUIA

(1752-1780)

\begin{tabular}{lrrrrr}
\hline & \multicolumn{2}{c}{ Bachiller } & & \multicolumn{2}{c}{ Ldo., Mtro., Dr. } \\
\cline { 2 - 3 } \cline { 5 - 5 } Rural & 797 & $84.9 \%$ & & 118 & $45.6 \%$ \\
Urbana & 142 & $15.1 \%$ & & 141 & $54.4 \%$ \\
Total & 939 & $100.0 \%$ & & 259 & $100.0 \%$ \\
\hline
\end{tabular}

NotA: Ldo. = Licenciado; Mtro. = Maestro; Dr. = Doctor. La muestra comprende a 96 bachilleres y 27 con grados mayores. Fuente: AHAY, CaC, v. 1-7. Se tomaron en cuenta los curatos de las gráficas 2 y 3.

siglo XIX ya sólo fue de $4 \%$. Una clara diferencia comparada con las cifras de México y Guadalajara por esos años. Esto es importante porque refleja nuevamente la formación endogámica del clero secular de Yucatán, en cuanto a estudios universitarios.

Los curas con grado mayor buscaron trabajar principalmente en parroquias urbanas, cerca de los centros de poder y colegios, donde algunos también se desempeñaron como catedráticos, aunque también laboraron en parroquias rurales. Es evidente su propensión a hacer una carrera eclesiástica de más horizontes que los bachilleres, como sucedía en el resto de los obispados novohispanos. ${ }^{80}$ En la segunda mitad del siglo XVIII, los curatos donde pasaron más años fueron los urbanos del Sagrario y la Sacristía de la catedral de Mérida, seguidos por el de San Cristóbal, extramuros de Mérida, Campeche, Valladolid y Santo Nombre de Jesús en Mérida (véase la gráfica 3). Entre 1752 y 1780, los curatos urbanos representaron el 54\% de los años de su servicio mientras que los rurales el restante $46 \%$ (véase el cuadro 2 ).

Pero llegar a ser cura de una parroquia pingüe podía ser la culminación de una trayectoria previa por parroquias relativamente pobres. Por ejemplo, el doctor Diego Antonio Lorra, graduado en Teología, fue teniente de cura por cinco años en la parroquia del Santo Nombre de Jesús, Mérida, en donde también se desempeñó como presidente de conferencias en el palacio episcopal. En 1748 prefirió migrar al oriente rural de Yucatán como cura de la parroquia de Xcan, que tenía una renta cercana a 800 pesos al año, cifra 50\% menor en comparación con el promedio de otros curatos en manos de doctores. Su suerte cambió cuando el obispo hizo visita pastoral

${ }^{80}$ Aguirre Salvador, El mérito y la estrategia, 269-391. 


\section{Gráfica 2}

RENTA APROXIMADA Y AÑOS SERVIDOS EN CURATOS

POR BACHILLERES, 1752-1780

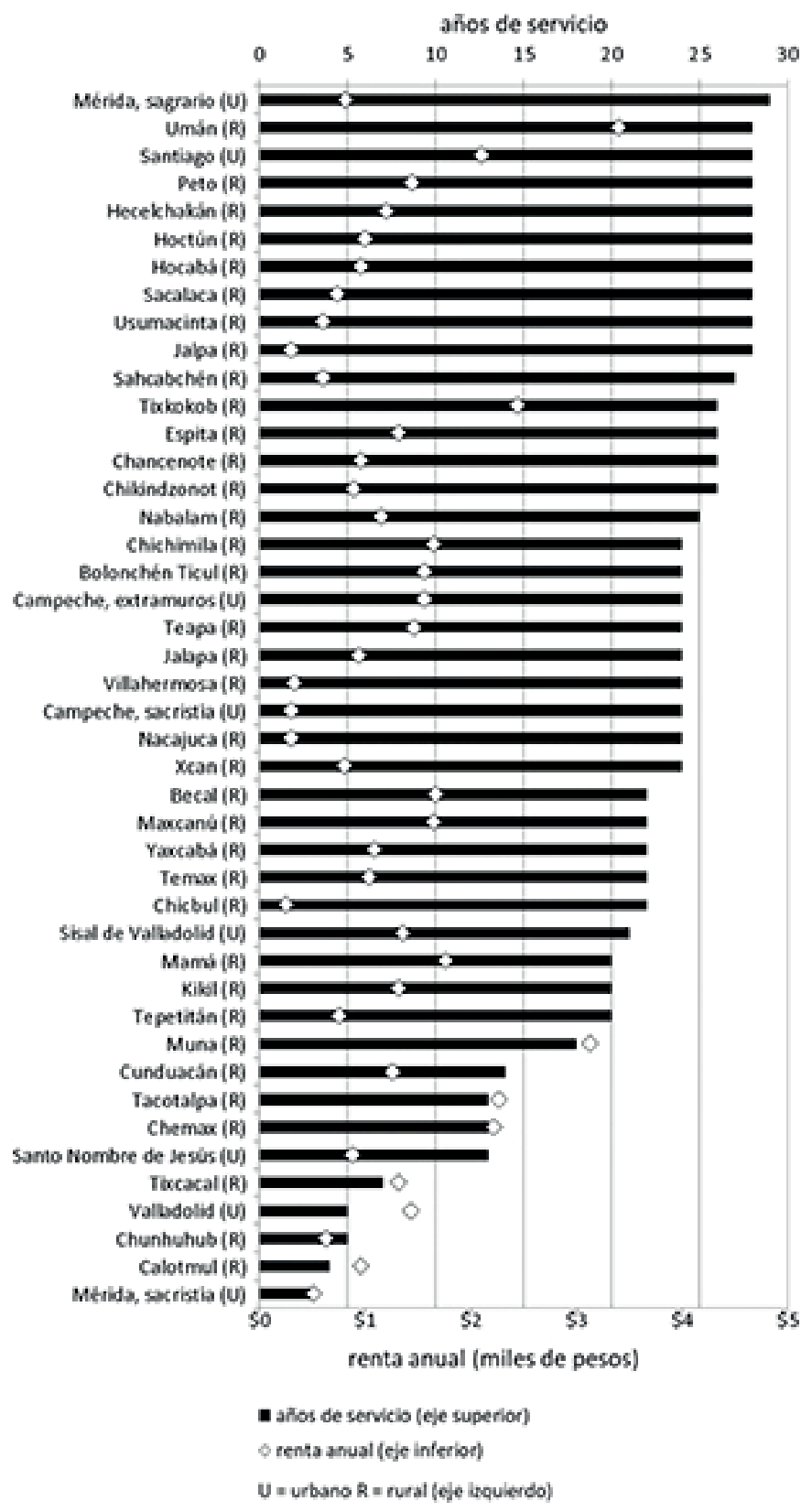

Fuente: AHAY, $\mathrm{CaC}$, v. 1-7. Véanse las rentas de los curatos en el apéndice. 


\section{Gráfica 3}

RENTAS APROXIMADAS Y TIEMPO SERVIDO EN CURATOS

POR LICENCIADOS, MAESTROS O DOCTORES (1752-1780)

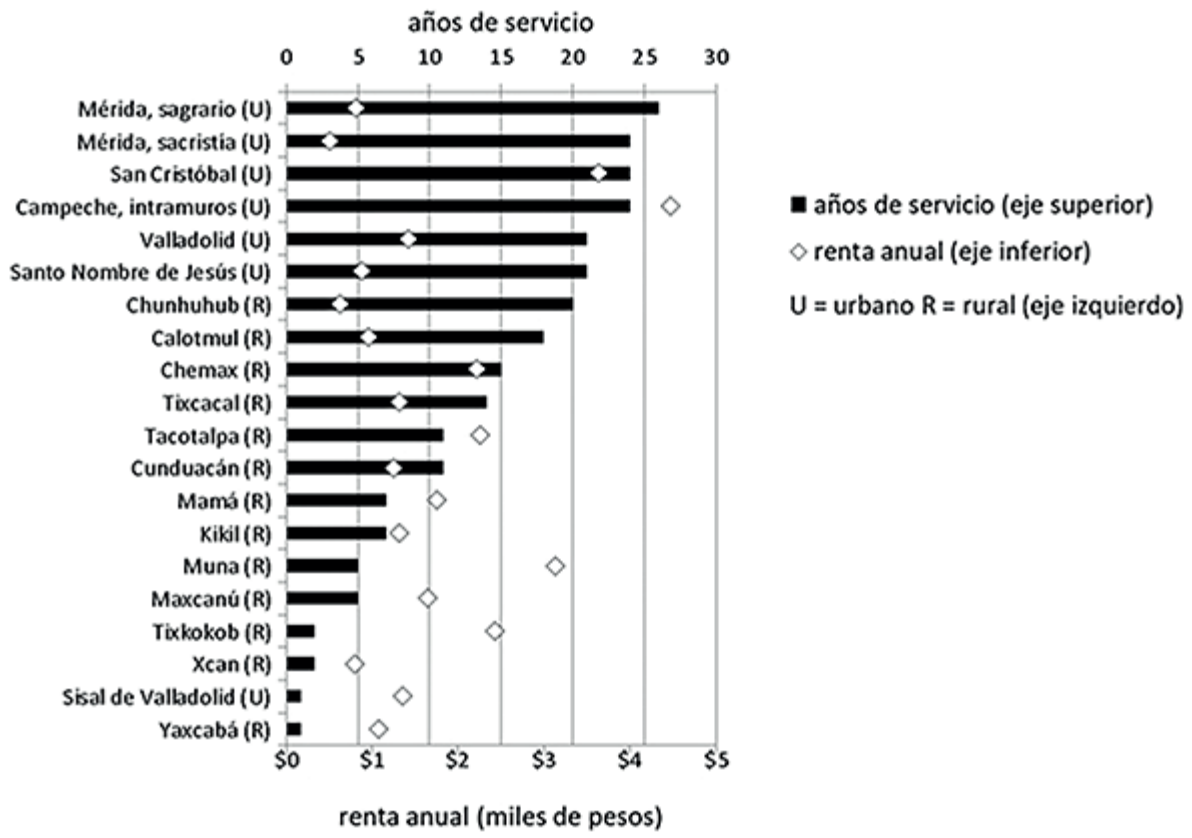

Fuente: Ahay, $\mathrm{CaC}$, v. 1-7. Véase el apéndice para las cifras. Para elaborar esta gráfica se estudió el caso de 27 clérigos graduados.

Cuadro 3

INGRESO PROMEDIO ANUAL, EN PESOS, DE LOS CURAS DE YUCATÁN Y TABASCO (1752-1780)

\begin{tabular}{lcc}
\hline & Bachiller & Ldo., Mtro., Dr. \\
\hline Rural & 1237 & 1467 \\
Urbana & 1187 & 1971 \\
Total & 1229 & 1742 \\
\hline
\end{tabular}

NotA: Ldo. = licenciado; Mtro. = maestro; Dr.= doctor.

Fuente: Ahay, CaC, v. 1-7. Se tomaron en cuenta los curatos del apéndice. 
en Xcan, en 1755, quedando admirado ya que, a pesar de ser pobre en rentas, Lorra había "...fabricado una primorosa y capaz iglesia de bóveda" con un culto "que no le excede ningún curato pingüe". ${ }^{81}$ Ese mismo año, el obispo convocó a concurso para ocupar más de una docena de curatos vacos, entre ellos siete beneficios recién secularizados que pertenecieron a los franciscanos. El doctor Lorra decidió buscar la titularidad de alguno de ellos y, en 1756, se le otorgó el más pingüe de todos, el de la antigua parroquia franciscana de San Cristóbal en Mérida, con un ingreso de 3600 pesos al año. ${ }^{82}$ Ya en su nuevo curato, fue el encargado de la construcción de un nuevo templo que estuviera fuera del conjunto conventual de los franciscanos. Los méritos que Lorra había acumulado en su trayectoria le valieron el puesto de cura en la ciudad episcopal. ${ }^{83}$ Los doctores también buscaron ser curas de la catedral de Mérida que, aunque de ingresos bajos, era una plataforma importante hacia el cabildo catedralicio, ${ }^{84}$ tendencia similar a la observada en otros obispados novohispanos en realidad. ${ }^{85}$

El ingreso promedio que los curas doctores disfrutaron fue de 1742 pesos, cifra $42 \%$ mayor a la de los bachilleres párrocos. Esta diferencia aumenta a 66\% si consideramos sólo las parroquias en los centros urbanos, pero baja a $19 \%$ en aquellas localizadas en las zonas rurales (véase el cuadro 3). Con todo, esos promedios fueron un aliciente fuerte para que los doctores buscaran los curatos urbanos, donde podían hallar mejores relaciones sociales con la élite provincial e impulsar sus carreras. ${ }^{86}$

Sin embargo, la renta recibida por este sector de curas, como se puede apreciar en la gráfica 3, no fue homogénea. Los doctores podían trabajar

${ }^{81}$ Real Biblioteca de Madrid, II/2843, Miscelánea de Manuel José Ayala, f. 7v-8. Visita del obispado de Yucatán hecha por su obispo el ilustrísimo señor don fray Ignacio Padilla, año de 1757.

${ }^{82}$ AHAY, CaC, v. 2, exp. 8, f. 260-261v.

${ }^{83}$ En la base circular interna de la bóveda principal de la iglesia de San Cristóbal, actualmente calle 50 x 67A y 69, Centro Histórico de Mérida, se encuentra la leyenda "EL Día 28 DE DICIEMBRE DE 1796 SE CONCLVYO LA FABRICA DE ESTA YGLESIA CVYOS PRIMEROS FVNDAMENTOS HAVIA LEBANTADO SV YA DIFUNTO CURA DOTOR DON DIEGO DE LORRA EL DIA 4 DE NOVIEMbRE DEL AÑo DE 1756". Véase también: Medina Suárez, "La consolidación del clero secular", 386-389.

${ }^{84}$ Los curas del sagrario tenían un ingreso anual ligeramente mayor a los 800 pesos. Véase el apéndice.

${ }^{85}$ Aguirre Salvador, El mérito y la estrategia, 269-391.

86 Taylor, Ministros de lo sagrado, v. I, 125, concluyó que los curas con grados superiores en las diócesis de México y Guadalajara de finales del siglo XVıI prefirieron trabajar en las parroquias de primera clase o cuando menos en parroquias cercanas a la capital diocesana. 
tanto en parroquias rurales con rentas bajas, como la de Chunhuhub de un poco más de 600 pesos al año, hasta pingües como la urbana de Campeche intramuros, con una renta aproximada de 4500 pesos anuales.

\section{El acceso al cabildo eclesiástico}

Los cabildos de las catedrales fueron corporaciones que, como la historiografía lo tiene bien estudiado, estuvieron constituidas por clérigos con altos grados académicos, trayectorias eclesiásticas notables, o bien, buenas relaciones e influencias para lograr prebendas o canonjías. Para la gran mayoría de ellos, el ascenso a catedral significó la culminación de sus carreras. En Yucatán, la consolidación de su cabildo eclesiástico tomó tiempo. En el siglo XVI los diezmos de donde salía su dotación eran tan bajos que la Corona tuvo que subsidiar la paga del obispo hasta 1596, cuando lo recaudado llegó a 8500 pesos.$^{87}$ No era una situación económicamente atrayente para el clero, particularmente si tenían que renunciar a puestos o actividades de mayores ingresos. En 1582 Rodrigo Muñoz, racionero en la catedral de México, renunció a la chantría de Mérida, probablemente por su baja renta que no compensaba su retiro de la capital. Con pocos recursos, el cuerpo capitular en Mérida no crecía, sólo contaba con dos prebendados además de Muñoz, ninguno criollo de la tierra. ${ }^{88}$

Con todo, al iniciar el siglo Xvir, los graduados de la región buscaron también el acceso a la catedral. En 1605, el obispo comunicó al rey que estaba el deanato, proponiendo entonces a tres graduados criollos. Éstos habían estudiado y obtenido en México algún grado, para luego regresar a su tierra y continuar su carrera eclesiástica. Sólo Pedro Sánchez de Aguilar

${ }^{87}$ En 1596 y 1597 la cuarta del obispo sobrepasó por 300 y 500 pesos los 500000 maravedís de retribución mínima que fijaba la ley xxxxıII, título vis, libro I de las Indias. Considerando que la cuarta era el $25 \%$ de los diezmos, se estimó que éstos debieron haber ascendido a alrededor de 8553 y 9353 pesos en esos años (utilizando una equivalencia de 1 peso $=272$ maravedís). Carta del obispo Juan Izquierdo al rey de 15 de junio de 1599, AGI, AM, 369. Este estimado era una cantidad baja comparada con lo diezmado en 1596 en las diócesis de México (35000 pesos), Puebla (40000 pesos), Michoacán (35000 pesos) y Oaxaca (15000 pesos). Véase Óscar Mazín Gómez, El cabildo catedral de Valladolid de Michoacán (Zamora: El Colegio de Michoacán, 1996), 105.

${ }^{88}$ Carta del obispo al rey de 1582, AGI, AM, 369. El obispo se quejó ese año de que Muñoz ya había pedido prórroga en dos ocasiones. Los otros dos prebendados eran el deán, licenciado Cristóbal Miranda, y el tesorero Leonardo González, originarios del puerto de Santa María y de Portugal respectivamente. 
contaba con el de doctor, lo que le valió ser designado como el nuevo deán, a pesar de no haber ocupado ningún puesto previo en el cabildo. ${ }^{89}$

Con la fundación de la universidad en 1624 los clérigos locales ya no necesitaron ir a graduarse a México para ocupar puestos del cabildo catedralicio. En 1643 dos bachilleres formados en aquélla ocuparon prebendas. ${ }^{90}$ En 1679, los siete capitulares habían estudiado en Yucatán: tres doctores y cuatro bachilleres. ${ }^{91}$ Los graduados de Mérida tomaron control de la influyente corporación eclesiástica.

Cabe destacar el papel de los obispos para que esto ocurriera, pues fueron sensibles a los intereses de la elite clerical local y su perfil académico, como sucedió con las canonjías de oficio. En diciembre de 1677, el rey ordenó que una de las dos canonjías de gracia que vacara en el futuro, debía convertirse en una magistral y, al vacar, en una doctoral, alternándose así. Este tipo de prebendas se designaba por oposición. De acuerdo con las leyes reales, la magistral debía ser ocupada por un teólogo y la doctoral por un canonista. Esto dejaba a los graduados de Yucatán fuera, pues su universidad no contaba con facultad de Cánones, como estuvo a punto de suceder en 1685. Sin embargo, el obispo intervino a su favor, informando al rey sobre “...el desconsuelo en que se hallan los patrimoniales de ese obispado, habiendo de observarse la alternativa en doctoral, respecto que allí sólo se estudia teología escolástica y moral...”, pidiendo entonces que, “...en lugar de la doctoral, sea esta canonjía penitenciaria o siempre magistral.... ${ }^{92}$ La penitenciaria también podía ser ocupada por teólogos. La petición tuvo éxito y en cédula

${ }^{89}$ Carta del obispo al rey de 12 de diciembre de 1605, AGI, AM, 369. Los tres presentados fueron el doctor Pedro Sánchez de Aguilar, cura de Chancenote, bachiller en artes en 1588, AGN, $R U$, v. 288, f. 10, y cánones en 1591, AGN, $R U$, v. 288, f. 17; el bachiller Francisco de Ávila, cura de Guaymango, graduado en artes, teología y cánones y el bachiller Bartolomé Jiménez de Tejeda, visitador y vicario general en Tabasco, graduado en cánones en 1601, AGN, RU, v. 288, f. 99. Las fechas de los grados en Armando Pavón Romero, "Universitarios y universidad en México en el siglo xvi" (tesis doctoral, Universidad de Valencia, 1995), 813, 827 y 840.

${ }^{90}$ Archivo del Venerable Cabildo Metropolitano de Yucatán (en adelante Avcmy), Acuerdos del Cabildo (en adelante AC), 3 de julio de 1643. Los bachilleres Pablo Domínguez de Sepúlveda y Alonso de Ojeda ocuparon los puestos de maestrescuela y canónigo respectivamente.

${ }^{91}$ Éstos fueron el bachiller Gaspar Gómez de Güemes, deán; el doctor Antonio de la Orta Barroso, arcediano; el bachiller Francisco Chacón Aguilar, chantre; el bachiller Fernando Pacheco de Benavidez, maestrescuela; el bachiller Juan Gómez Briseño, canónigo; el doctor Juan de Villarreal y Roxas, canónigo, y el bachiller Nicolás de Salazar, racionero. AVCMY, Acuerdos del Cabildo, 9 de enero de 1679.

${ }^{92}$ La cédula real de 26 de diciembre de 1686, con informaciones insertas de la carta del obispo de 1 de junio de 1685 y de la cédula real de 24 de diciembre de 1677, en Carrillo y Ancona, El obispado de Yucatán, t. 2, 600. 
de 26 de diciembre de 1686, el rey resolvió que la canonjía de oposición se alternara entre la magistral y la penitenciaria, omitiendo la doctoral.

En el siglo XVIII, la canonjía de oposición se consolidó como una vía de ascenso al cabildo de los doctores yucatecos, si bien hubo prebendas también asignadas a clérigos de otros obispados. Por ejemplo, en 1760, de ocho prebendados, seis se graduaron en Mérida, uno provino de España y otro se desconoce dónde se graduó, pero fue colegial de San Pedro en Mérida. ${ }^{93}$

En 1768, ante el cierre de la universidad jesuita, el obispo Antonio Alcalde solicitó a Carlos III que el Seminario Tridentino fuera su nueva sede. La restauración de las facultades era muy importante para los clérigos al asegurar la obtención regular de los grados, argumentó el prelado, “...sin cuyo preciso requisito no podían oponerse a las canonjías de oficio". ${ }^{94} \mathrm{La}$ solicitud fue apoyada por diversas autoridades seglares y eclesiásticas yucatecas y tuvo éxito: el rey, en cédula de 6 de mayo de 1778, aceptó la propuesta. Sin embargo, diversos problemas retrasaron la reapertura. En consecuencia, el cabildo eclesiástico planteó al rey, en 1788, que en el obispado sólo había dos o tres doctores, por lo que solicitó dispensar el requisito de los grados para concursar a la canonjía de oficio. El temor era que doctores de otras diócesis ganaran el concurso. Pero el rey denegó la solicitud, declarando que no se habían justificado los obstáculos para abrir la universidad en el seminario tridentino. ${ }^{95}$ El temor de la clerecía yucateca se cumplió cuando en 1795, el doctor Santiago Martínez de Peralta, originario de la península ibérica, ocupó esa canonjía. ${ }^{96}$

El alto clero de Yucatán resintió la "intrusión” y actuó en consecuencia, demostrando nuevamente el gran valor de los grados académicos en sus carreras. Al volver a quedar vacante esa canonjía, el clero local se alistó para ocuparla nuevamente. Aunque se presentaron tres concursantes, sólo uno

${ }^{93}$ Los prebendados fueron el deán doctor Joseph Martínez, el arcediano doctor Buenaventura Monreal, el chantre doctor Pedro de Zetina, el maestrescuela Joseph de Alarcón, los canónigos doctor Francisco Xavier de la Peña y bachiller Juan Antonio de Mendicute y los racioneros doctor Agustín Carrillo Pimentel y doctor Agustín Francisco de Echano. AVCMY, AC, 24 de julio de 1760, f. 156v-161.

${ }^{94}$ Texto inserto en cédula real al deán y cabildo de la iglesia catedral de Mérida de Yucatán de 6 de mayo de 1778, AHAY, Cédulas Reales (en adelante CR), caja sin número, exp. 2, f. 203.

95 Texto inserto en la cédula real al deán y cabildo de Mérida de 4 de diciembre de 1789 , AHAY, CR, caja sin número, exp. 4, f. 378-379. Uno de los obstáculos a los que aludía el obispo era la falta de fondos, aunque este argumento ha sido cuestionado por Laura Machuca Gallegos, "El proyecto educativo en Yucatán a fines del siglo XVIII y principios del xIX: el seminario y la casa de estudios”, en Espacios de saber, espacios de poder, 409.

${ }^{96}$ Carrillo y Ancona, El obispado de Yucatán, t. 2, 952. 
poseía el grado de doctor: Lucas Ribas y López, natural de Mérida y quien, a sus 62 años, alcanzó aún a graduarse en la universidad jesuita. El segundo fue Ignacio Zepeda, de Mérida también, cura de San Cristóbal, quien estudió en el Seminario Tridentino de San Ildefonso, pero sin graduarse todavía. Por ello, viajó a Cuba, en donde recibió los tres grados de Teología en la Universidad de La Habana. El tercer opositor fue Eduardo Cárdenas, originario de Tabasco, quien debió viajar a Guatemala por seis meses para graduarse de licenciado y doctor en Teología por la Universidad de San Carlos. ${ }^{97}$ En febrero de 1806 fue propuesto en primer lugar el doctor Zepeda. Su viaje a La Habana había rendido frutos.

\section{Reflexiones finales}

En el imperio español las universidades y los colegios jesuitas tuvieron un papel por demás relevante en la formación del clero secular. Las disposiciones del Concilio de Trento y las leyes reales dispusieron el tipo de educación que ese clero debía poseer, tanto para la administración espiritual de los fieles como para ocupar cargos y beneficios eclesiásticos. Sobre estos últimos, debían preferirse en América los graduados en las universidades de México, Lima o Castilla, según lo estipuló la cédula del patronato de 1574. Más específicamente, para las canonjías de oficio se debía optar por teólogos y canonistas y, de acuerdo con el Concilio de Trento, éstos debían poseer los grados mayores de licenciados o doctores. La exigencia de grados universitarios para las prebendas y canonjías catedralicias se hizo extensiva a los curatos, al convertirse esos títulos, no sólo en un mérito, sino en una prueba de posesión de conocimientos y doctrina necesarios en la carrera eclesiástica. Si bien esos títulos no fueron el único mérito para quienes hacían carrera, pues hubo otros de igual peso, sí puede considerarse como una carta de presentación formal para que el individuo comenzara a ser tomado en cuenta en los ascensos eclesiásticos, como lo prueban las consultas en el Consejo de Indias.

La demanda de grados por la clerecía indiana no hizo sino crecer con el tiempo, por lo cual en provincias alejadas de las universidades de Lima

${ }^{97}$ El expediente del concurso en AHAY, CaC, v. 21, exp. 130, f. 1-36. El obispo Estévez en una carta posterior, de 9 de febrero de 1806, mencionó que “...el doctor Cárdenas pasó a Guatemala caminos fragosos de cuatrocientas leguas o más en que gastó dinero y seis meses...”, lo que hubiera excusado reabriendo la universidad en Yucatán. Véase Domínguez y Uc, “Los proyectos de enseñanza", 90-91. 
y México surgieron voces sobre la necesidad de contar con estudios mayores en establecimientos educativos que además pudieran dispensar grados. La Corona fue sensible a tales voces y permitió entonces el establecimiento de universidades en colegios dominicos y jesuitas en provincias al menos 200 millas alejadas de las universidades reales, como fue el caso de Mérida de Yucatán en 1624. Cabe mencionar que este tipo de universidades tuvieron como principal propósito la enseñanza de Artes y Teología, si bien más adelante algunas buscaron instaurar cátedras de Cánones y Leyes, aunque con resultados mixtos, como sucedió en Mérida.

El caso de la Universidad de Mérida aquí estudiado brinda elementos valiosos para entender la gran importancia que tuvo en la consolidación de una clerecía propia del obispado de Yucatán. En primer lugar porque evitó que los clérigos tuvieran que trasladarse lejos de sus familias y ciudades para estudiar y graduarse, como sucedió antes de 1624. En segundo lugar, porque al poder obtener grados localmente, se les facilitó el inicio de una trayectoria eclesiástica a una edad temprana. En tercer lugar, porque los grados redondearon la formación de una clerecía patrimonial; es decir, originaria del obispado y que formaba parte de las familias vecinas, que estuvo en mejores condiciones de cohesionarse alrededor de intereses comunes, como por ejemplo, presionar a las autoridades, reales y eclesiásticas, para ampliar los beneficios eclesiásticos a que se sentían acreedores. Y en especial las parroquias de indios, aun si para ello debían también impulsar la secularización de las múltiples doctrinas franciscanas. En cuarto lugar, porque con los grados, la clerecía de Yucatán pudo equipararse a sus similares de otros obispados para no desmerecer en sus méritos y sus aspiraciones de cargos y prebendas. Y, en quinto lugar, porque con ellos, también pudieron argumentar estar capacitados, como los franciscanos, para hacerse cargo de toda la administración espiritual de los indios.

La mayoría de los clérigos de Yucatán fueron bachilleres en Artes, el grado menos costoso en tiempo y recursos para emprender una carrera en las parroquias. Aquellos con grados de licenciado o doctor, tal y como sucedía en otros obispados, estuvieron en mejores condiciones de alcanzar las mejores parroquias urbanas o de mayores rentas, así como las cátedras, los cargos en la mitra y las codiciadas prebendas y canonjías. Yucatán no fue un obispado deseado por los clérigos letrados del centro de Nueva España o de otras regiones, de ahí que sus cargos y beneficios eclesiásticos normalmente recayeron en la clerecía local. 
APÉNDICE

Rentas aproximadas en CURATOS DE YUCATÁN y TABASCO (1752-1780)

\begin{tabular}{lclrlr}
\hline \multicolumn{1}{c}{ Curato } & $\begin{array}{c}\text { Renta } \\
\text { anual } \\
\text { (pesos) }\end{array}$ & Curato & $\begin{array}{r}\text { Renta } \\
\text { anual }\end{array}$ & Curato & $\begin{array}{r}\text { Renta } \\
\text { anual }\end{array}$ \\
\hline Campeche, intramuros & 4480 & Peto & 1440 & Chikindzonot & 888 \\
Umán & 3396 & Valladolid & 1420 & $\begin{array}{l}\text { Santo Nombre } \\
\text { de Jesús }\end{array}$ & 876 \\
San Cristóbal & 3636 & $\begin{array}{l}\text { Sisal de } \\
\text { Malladolid }\end{array}$ & 1356 & Mérida, Sagrario & 816 \\
Muna & 3132 & Tixcacal & 1320 & Xcan & 800 \\
Tixkokob & 2436 & Espita & 1316 & Tepetitán & 752 \\
Tacotalpa & 2262 & Cunduacán & 1254 & Sacalaca & 736 \\
Chemax & 2220 & Hecelchakán & 1200 & Chunhuhub & 624 \\
Santiago & 2100 & Nabalam & 1152 & Usumacinta & 600 \\
Mamá & 1758 & Yaxcabá & 1080 & Sahcabchén & 600 \\
Becal & 1668 & Temax & 1032 & Villahermosa & 324 \\
Chichimila & 1644 & Hoctún & 996 & Campeche, & 300 \\
& & & & sacristía & \\
Maxcanú & 1644 & Hocabá & 960 & Nacajuca & 300 \\
Bolonchen Ticul & 1560 & Chancenote & 960 & Jalpa & 300 \\
Campeche, & 1560 & Calotmul & 954 & Chicbul & 246 \\
extramuros & & Jalapa & 936 & & \\
Teapa & 1464 & & &
\end{tabular}

Fuentes: Informes de mesadas, AHAY, $\mathrm{CaC}$, v. 1-7. Para Campeche intramuros y Xcan, informes de los curas encargados de las parroquias, en AHAY, CaC, v. 7, exp. 19, f. 119-119v, y v. 2, exp. 8, f. 260-261v, respectivamente.

Nota metodológica: Las rentas anuales se calcularon de las mesadas excepto en los casos de Campeche intramuros y Xcan en que se tomaron los datos que proveyeron directamente los curas. La renta en un año dado se consideró como un acercamiento para el periodo; pero, cuando hubo datos para diferentes años, se tomó el promedio de las rentas. Las cantidades pueden estar ajustadas si se incluía o no la conducción de las mismas. En el caso de no conocerse la mesada o los años trabajados por los graduados, el curato fue omitido. Los beneficios estudiados fueron aquellos ya establecidos hasta finales de la década de los 1750's. Se trató de una muestra de 47 de 57 beneficios. Dada la naturaleza de los datos y que no existen datos de las rentas en cada año del periodo estudiado, las cantidades deben de ser consideradas como aproximaciones y no números exactos. Un primer reporte de las mesadas en Fallon, "The Secular Clergy”, 44. 


\section{FUENTES}

Archivos y siglas

AGEY, $C, I, \quad$ Archivo General del Estado de Yucatán, Mérida, Yucatán, México: Fondo Colonial, Sección Iglesia.

AGI, $A M \quad$ Archivo General de Indias, Sevilla, España: Fondo Audiencia de México.

AGI, $C \quad$ Archivo General de Indias, Sevilla, España: Fondo Contratación.

AGI, IG Archivo General de Indias, Sevilla, España: Fondo Indiferente General.

AGI, $P R$

Archivo General de Indias, Sevilla, España: Fondo Patronato Real.

AGN, $I V$

Archivo General de la Nación, Ciudad de México, México: Fondo Indiferente Virreinal.

AGN, $J \quad$ Archivo General de la Nación, fondo Jesuitas, Ciudad de México.

AGN, $R U$ Archivo General de la Nación, fondo Ramo Universidad, Ciudad de México.

aHaY, $\mathrm{CaC}$ Archivo Histórico del Arzobispado de Yucatán, Fondo Concurso a Curatos, Mérida, Yucatán.

AHAY, CR Archivo Histórico del Arzobispado de Yucatán, Fondo Cédulas Reales, Mérida, Yucatán.

AhaY, $G$ Archivo Histórico del Arzobispado de Yucatán, Fondo Gobierno, Mérida, Yucatán.

Ahay, OyD Archivo Histórico del Arzobispado de Yucatán, Fondo Oficios y Decretos, Mérida, Yucatán.

AHAY, ByO Archivo Histórico del Arzobispado de Yucatán, Fondo Becas y Órdenes, Mérida, Yucatán.

AHN, C Archivo Histórico Nacional, Madrid, España: Fondo Códices.

AHN, DC Archivo Histórico Nacional, Fondo Diversos-Colecciones, Madrid.

AhPmCj Archivo Histórico de la Provincia Mexicana de la Compañía de Jesús, Ciudad de México, México.

ANCH, JA Archivo Nacional de Chile, Santiago de Chile, Chile: Fondo Jesuitas de América.

ARSI, NRQ Archivum Romanum Societatis Iesu, Roma, Italia: Fondo Nuevo Reino y Quito. 
Avcmy, AC Archivo del Venerable Cabildo Metropolitano de Yucatán, Mérida, Yucatán, México: Fondo Acuerdos del Cabildo.

RAH, $P J$

Real Academia de la Historia, Madrid, España: Fondo Colección Papeles Jesuitas.

RBM, MMJA

Real Biblioteca de Madrid, España: Fondo Miscelánea de Manuel José Ayala.

\section{Bibliografía}

Adams, Eleanor B. "Note on the life of Francisco de Cárdenas Valencia." The Americas, v. 2, n. 1 (1945): 21-29.

Aguirre Salvador, Rodolfo. "El ascenso de los clérigos de Nueva España durante el gobierno del arzobispo José Lanciego y Eguilaz.” Estudios de Historia Novohispana, 22 (2000): 77-110. DoI: http://dx.doi.org/10.22201/iih.24486922e. 2000.022.3515.

Aguirre Salvador, Rodolfo. El mérito y la estrategia. Clérigos, juristas y médicos en la Nueva España. México: Universidad Nacional Autónoma de México, Centro de Estudios sobre la Universidad; México: Plaza y Valdés Editores, 2003.

Aguirre Salvador, Rodolfo. "Formación y ordenación de clérigos ante la normativa conciliar. El caso del arzobispado de México, 1712-1748.” En Los concilios provinciales en Nueva España. Reflexiones e influencias, coordinación de María del Pilar López-Cano y Francisco Javier Cervantes Bello, 337-362. México: Universidad Nacional Autónoma de México, Instituto de Investigaciones Históricas; Puebla: Benemérita Universidad Autónoma de Puebla, 2005.

Aguirre Salvador, Rodolfo. "La demanda de clérigos lenguas en el arzobispado de México, 1700-1750." Estudios de Historia Novohispana, 35 (2006): 47-70. DoI: http://dx.doi.org/10.22201/iih.24486922e.2006.035.3650.

Aguirre Salvador, Rodolfo. Un clero en transición. Población clerical, cambio parroquial y política eclesiástica en el arzobispado de México, 1700-1749. México: Universidad Nacional Autónoma de México, Instituto de Investigaciones sobre la Universidad y la Educación; México: Bonilla Artigas Editores; Madrid: Iberoamericana Vervuert, 2012.

Aguirre Salvador, Rodolfo. "El sínodo de Yucatán para la reforma del clero: entre la política borbónica y los intereses regionales.” En Reformas y resistencias en la Iglesia novohispana, coordinación de María del Pilar Martínez López-Cano y Francisco Javier Cervantes Bello, 251-284. México: Universidad Nacional Autónoma de México, Instituto de Investigaciones Históricas; Puebla: Benemérita Universidad Autónoma de Puebla, 2014. 
Cárdenas Valencia, Francisco de. Relación historial eclesiástica de la Provincia de Yucatán en la Nueva España, escrita el año de 1639. México: Antigua Librería Robredo de José Porrúa e Hijos, 1937.

Carrillo y Ancona, Crescencio. El obispado de Yucatán. Historia de su fundación y de sus obispos desde el siglo XVI hasta el XIX, 2 t. Mérida: Imprenta y Litografía R. Caballero. Reedición Fondo Editorial de Yucatán, 1979.

Domínguez Saldívar, Roger A., y Manuel Jesús Uc Sánchez. "Los proyectos de enseñanza superior en Yucatán durante la crisis del régimen colonial (1803-1824).” En Historia de la educación superior en Yucatán: las instituciones (universidad, colegio e instituto), siglos XIX y XX. Coordinación de Jorge I. Castillo Canché, Roger A. Domínguez Saldívar y José E. Serrano Catzim, 85-110. Mérida: Universidad Autónoma de Yucatán, Facultad de Ciencias Antropológicas, 2017.

Fallon, Michael Joseph. "The Secular Clergy in the Diocese of Yucatan: 1750-1800.” Tesis de doctorado, The Catholic University of America, Washington, 1979.

García Bernal, María Cristina. Yucatán. Población y encomienda bajo los Austrias. Sevilla: Consejo Superior de Investigaciones Científicas, Escuela de Estudios Hispano-Americanos, 1978.

Gómez de Parada, Juan. Constituciones sinodales del obispado de Yucatán. Transcripción, edición y notas de Gabriela Solís Robleda. Mérida: Universidad Nacional Autónoma de México, Centro Peninsular en Humanidades y Ciencias Sociales, 2008.

Gonzalbo Aizpuru, Pilar. Historia de la educación en la época colonial. La educación de los criollos y la vida urbana. México: El Colegio de México, 1990. Doi: $10.2307 /$ j.ctv47w4n0.

González Cicero, Stella María. Perspectiva religiosa en Yucatán, 1517-1571: Yucatán, los franciscanos y el primer obispo fray Francisco del Toral. México: El Colegio de México, 1978.

González González, Enrique. El poder de las letras. Por una historia social de las universidades de la América hispana en el periodo colonial. En colaboración con V. Gutiérrez Rodríguez. México: Universidad Nacional Autónoma de México Instituto de Investigaciones sobre la Universidad y la Educación; Puebla: Benemérita Universidad Autónoma de Puebla; México: Universidad Autónoma Metropolitana; México: Ediciones Educación y Cultura, 2017.

Harrington, Raymond P. "The Secular Clergy in the Diocese of Mérida de Yucatán, 1780-1850: Their Origins, Careers, Wealth and Activities.” Tesis de doctorado, The Catholic University of America, Washington, 1982.

Hernández de Alba, Guillermo. Documentos para la historia de la educación en Colombia. Tomo 1, 1540-1653. Bogotá: Patronato Colombiano de Artes y Ciencias, 1969. 
Kagan, Richard L. Universidad y sociedad en la España moderna. Madrid: Tecnos, 1981.

Lanning, John Tate. Reales cédulas de la Real y Pontificia Universidad de San Carlos de Guatemala. Guatemala: Universidad de San Carlos de Guatemala, Editorial Universitaria, 1954.

Machuca Gallegos, Laura. Los hacendados de Yucatán 1785-1847. México: Centro de Investigaciones y Estudios Superiores en Antropología Social, 2011.

Machuca Gallegos, Laura. "El proyecto educativo en Yucatán a fines del siglo XviII y principios del XIX: el seminario y la casa de estudios.” En Espacios de saber, espacios de poder. Iglesias, universidades y colegios en Hispanoamérica, siglos XVIXIX, coordinación de Rodolfo Aguirre Salvador, 399-420. México: Universidad Nacional Autónoma de México, Instituto de Investigaciones sobre la Universidad y la Educación; México: Bonilla Artigas Editores; Madrid: Iberoamericana Vervuert, 2013.

Mayer, Alicia. "Modernidad y tradición, ciencia y teología. Francisco Javier Alegre y las institutionum theologicarum." Estudios de Historia Novohispana, 47 (2012): 93-126. DoI: http://dx.doi.org/10.22201/iih.24486922e.2012.47.36082.

Mazín Gómez, Óscar. El cabildo catedral de Valladolid de Michoacán. Zamora: El Colegio de Michoacán, 1996.

Medina Suárez, Víctor Hugo. "La consolidación del clero secular en el obispado de Yucatán, siglo XVIII.” Tesis de doctorado en Historia, El Colegio de Michoacán, Zamora, 2014.

Ortiz Rubio, Luis Raúl. "En resguardo de los bienes y el alma. La fundación de capellanías en Yucatán durante los siglos XVII y XVIII.” Tesis de maestría en Historia, Centro de Investigaciones y Estudios Superiores en Antropología Social, Mérida, 2016.

Patch, Robert W. Maya and Spaniard in Yucatan, 1642-1812. Stanford: Stanford University, 1994.

Patrón Sarti, Rafael. "La Universidad de Mérida de Yucatán en la época colonial: documentos probatorios de su existencia”. Historias, n. 80 (2011): 47-61.

Patrón Sarti, Rafael, ed. La Universidad de Mérida de Yucatán. Relación de los actos y fiestas de fundación en 1624. Mérida: Ediciones de la Universidad Autónoma de Yucatán, 2013.

Patrón Sarti, Rafael, invest., transcripción y notas. La licencia real de fundación del Colegio Seminario de San Pedro en Mérida de Yucatán, 1711. Mérida: Ediciones de la Universidad Autónoma de Yucatán, 2014.

Patrón Sarti, Rafael, y Enrique González González. "El Capitán Martín de Palomar, regidor, encomendero y benefactor: su testamento (Mérida, Yucatán, 1611).” 
Estudios de Historia Novohispana, 43 (2010): 185-252. DoI: http://dx.doi. org/10.22201/iih.24486922e.2010.043.23475.

Pavón Romero, Armando. "Universitarios y universidad en México en el siglo xvi." Tesis doctoral, Universidad de Valencia, Valencia, 1995.

Pérez Puente, Leticia, Enrique González González y Rodolfo Aguirre Salvador. "Estudios, textos y anexos. I y II concilios." En Concilios provinciales mexicanos. Época colonial, coordinación de María del Pilar Martínez López-Cano, edición en disco compacto. México: Universidad Nacional Autónoma de México, Instituto de Investigaciones Históricas, 2004.

Pérez Puente, Leticia, Enrique González González y Rodolfo Aguirre Salvador. "Los concilios provinciales mexicanos primero y segundo." En Los concilios provinciales en Nueva España. Reflexiones e influencias, coordinación de María del Pilar Martínez López-Cano y Francisco Javier Cervantes Bello, 17-40. México: Universidad Nacional Autónoma de México; Puebla: Benemérita Universidad Autónoma de Puebla, 2005.

Peset, Mariano, y Juan Gutiérrez Cuadrado. "Clérigos y juristas en la Baja Edad Media castellano-leonesa”. Senara. Revista de Filología, anexo 2, v. 3, (1981): 7-66.

Ricard, Robert. La conquista espiritual de México: ensayo sobre el apostolado y los métodos misioneros de las órdenes mendicantes en la Nueva España de 1523-1524 a 1572. México: Fondo de Cultura Económica, 2005.

Rocher Salas, Adriana. "Frailes y clérigos en Yucatán. Siglo xvir." Hispania Sacra, 55 (2003): 599-625. https://doi.org/10.3989/hs.2003.v55.i112.159.

Rocher Salas, Adriana. "La política eclesiástica regia y sus efectos en la diócesis de Yucatán.” Revista Complutense de Historia de América 30 (2004): 53-76.

Rocher Salas, Adriana. "Las doctrinas de indios: la llave maestra del Yucatán colonial.” En La Iglesia hispanoamericana de la Colonia a la República. Coordinación de Rodolfo Aguirre y Lucrecia Enríquez, 71-98. México: Universidad Nacional Autónoma de México, Instituto de Investigaciones sobre la Universidad y la Educación; Santiago de Chile: Pontificia Universidad Católica de Chile; México: Plaza y Valdés, 2008.

Rocher Salas, Adriana. La disputa por las almas. Las órdenes religiosas en Campeche, siglo XVIII. México: Consejo Nacional para la Cultura y las Artes, 2010.

Rocher Salas, Adriana. "Para lo divino y para lo humano: los colegios jesuitas de Yucatán.” En Espacios de saber, espacios de poder. Iglesias, universidades y colegios en Hispanoamérica, siglos XVI-XIX. Coordinación de Rodolfo Aguirre Salvador, 259-288. México: Universidad Nacional Autónoma de México, Instituto de Investigaciones sobre la Universidad y la Educación; México: Bonilla Artigas Editores; Madrid: Iberoamericana Vervuert Editorial, 2013. 
Rocher Salas, Adriana. "Clero y élites en Yucatán durante el periodo colonial." En Grupos privilegiados en la península de Yucatán, siglos XVIII y XIX, coordinación de Laura Machuca Gallegos, 21-53. México: Centro de Investigaciones y Estudios Superiores en Antropología Social; Mérida: Secretaría de Cultura y las Artes de Yucatán, 2014.

Serrano Catzim, José. E., y Jorge I. Castillo Canché. "La universidad literaria de Mérida a través de su reglamentación (1824-1854).” En Historia de la educación superior en Yucatán: las instituciones (universidad, colegio e instituto), siglos XIX y Xx. Coordinación de Jorge I. Castillo Canché, Roger A. Domínguez Saldívar y José E. Serrano Catzim, 141-180. Mérida: Universidad Autónoma de Yucatán, Facultad de Ciencias Antropológicas, 2017.

Solano y Pérez Lila, Francisco de. "La población indígena de Yucatán durante la primera mitad del siglo xvII." Anuario de Estudios Americanos, xxviII (1971): 168-190.

Taylor, William B. Ministros de lo sagrado. Sacerdotes y feligreses en el México del siglo XVIII. México: El Colegio de Michoacán; México: Secretaría de Gobernación; México: El Colegio de México, 1999.

Teruel Gregorio de Tejada, Manuel. Vocabulario básico de la historia de la Iglesia. Madrid: Crítica, 1993.

Valle Pimentel, Miguel. "Agustín Pablo de Castro, 1728-1790. Vida y semblanza." Tesis de maestría en Letras Españolas, Universidad Iberoamericana, México, 1962.

\section{SOBRE LOS AUTORES}

\section{Rafael Patrón Sarti}

Maestro en Economía Agrícola por la Universidad de Oxford y doctor por la Universidad de Reading, Inglaterra. Ha trabajado en el rescate histórico de la Universidad de Mérida en la época colonial por más de una década publicando los primeros resultados en revistas especializadas como Estudios de Historia Novohispana del Instituto de Investigaciones Históricas de la Universidad Nacional Autónoma de México, así como en Historias del Instituto Nacional de Antropología e Historia de México. En 2013 editó el libro La Universidad de Mérida de Yucatán. Relación de los actos y fiestas de fundación en 1624 en la Universidad Autónoma de Yucatán, institución donde labora actualmente. 
Rodolfo Aguirre Salvador

Investigador titular del Instituto de Investigaciones sobre la Universidad y la Educación de la Universidad Nacional Autónoma de México. Dirige seminarios en los posgrados de Historia y de Pedagogía de la misma universidad. Desde 2001 es miembro del Sistema Nacional de Investigadores. Sus líneas de investigación son la historia social y política de la Iglesia en Nueva España y la historia de la Real Universidad de México. Entre sus últimas publicaciones se hallan los libros de autor: Cofradías y asociaciones de fieles en la mira de la Iglesia y de la Corona. Arzobispado de México, 16801750 y Un desafío a la Real Universidad de México. El arribo de grupos de bajo rango social. 